Prepared in cooperation with the Bureau of Land Management, Nevada Department of Wildlife, and U.S. Fish and Wildlife Service

Monitoring and Research on the Bi-State Distinct Population Segment of Greater Sage-Grouse (Centrocercus urophasianus) in the Pine Nut Mountains, California and Nevada-Study Progress Report, 2011-15

Open-File Report 2015-1222

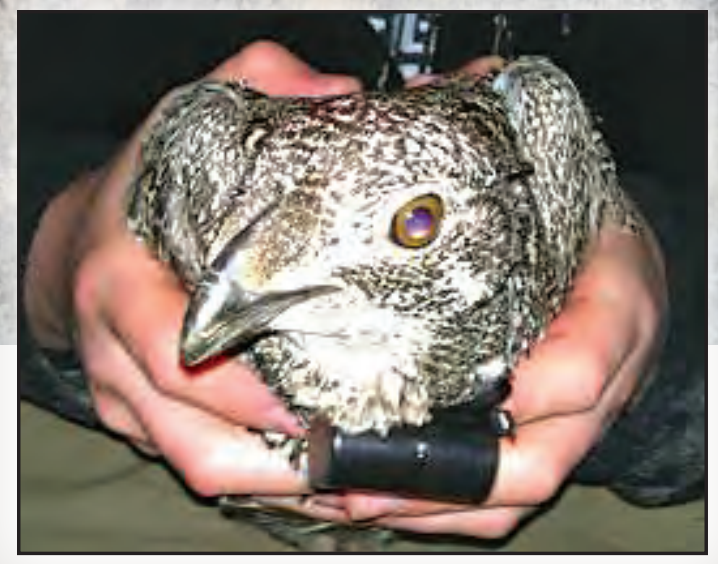


Cover: Mill Canyon lek in the Pine Nut Mountains study area. Inset: Radio collared Greater sage-grouse.

Photographs by Brian G. Prochazka, U.S. Geological Survey. 


\section{Monitoring and Research on the Bi-State Distinct Population Segment of Greater Sage-Grouse (Centrocercus urophasianus) in the Pine Nut Mountains, California and Nevada-Study Progress Report, 2011-15}

By Peter S. Coates, Katie M. Andrle, Pilar T. Ziegler, and Michael L. Casazza

Prepared in cooperation with the Bureau of Land Management, Nevada Department of Wildlife, and U.S. Fish and Wildlife Service

Open-File Report 2015-1222 


\section{U.S. Department of the Interior \\ SALLY JEWELL, Secretary}

\section{U.S. Geological Survey \\ Suzette M. Kimball, Director}

U.S. Geological Survey, Reston, Virginia: 2016

For more information on the USGS-the Federal source for science about the Earth, its natural and living resources, natural hazards, and the environment-visit http://www.usgs.gov/ or call 1-888-ASK-USGS (1-888-275-8747).

For an overview of USGS information products, including maps, imagery, and publications, visit http://www.usgs.gov/pubprod/.

Any use of trade, firm, or product names is for descriptive purposes only and does not imply endorsement by the U.S. Government.

Although this information product, for the most part, is in the public domain, it also may contain copyrighted materials as noted in the text. Permission to reproduce copyrighted items must be secured from the copyright owner.

Suggested citation:

Coates, P.S., Andrle, K.M., Ziegler, P.T., and Casazza, M.L., 2016, Monitoring and research on the Bi-State Distinct Population Segment of greater sage-grouse (Centrocercus urophasianus) in the Pine Nut Mountains, California and Nevada-Study progress report, 2011-15: U. S. Geological Survey Open-File Report 2015-1222, 40 p., http://dx.doi.org/10.3133/ofr20151222.

ISSN 2331-1258 (online) 


\section{Contents}

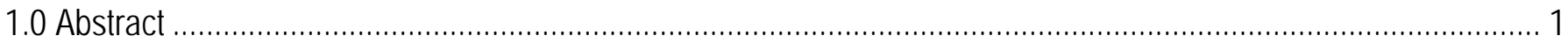

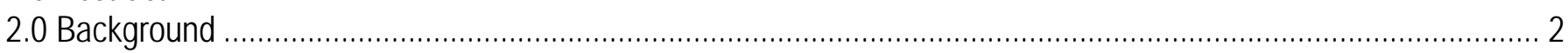

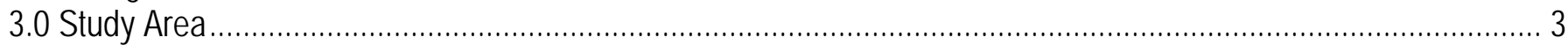

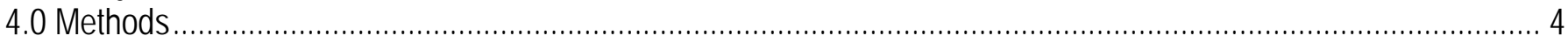

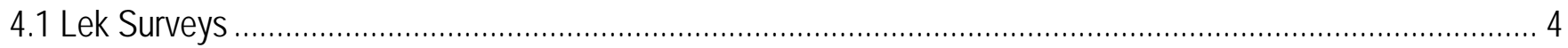

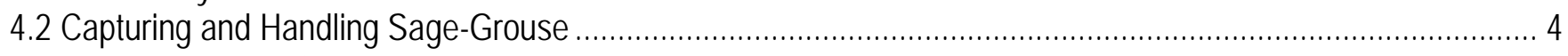

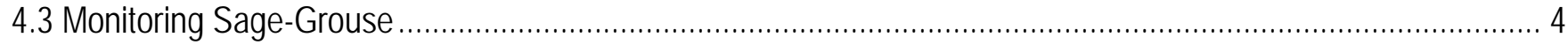

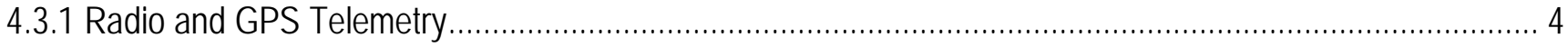

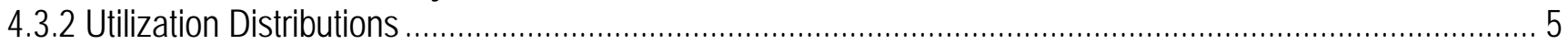

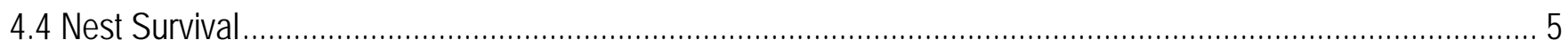

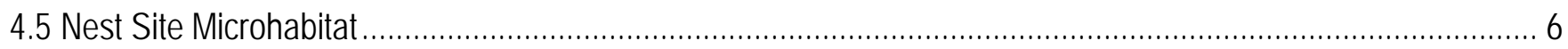

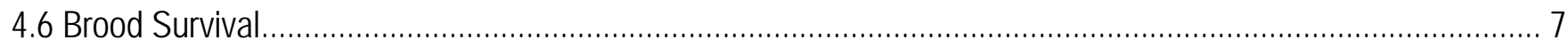

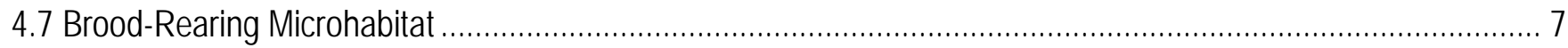

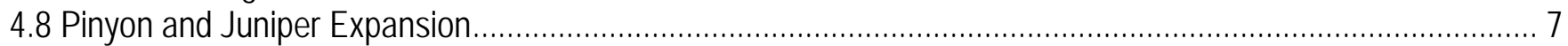

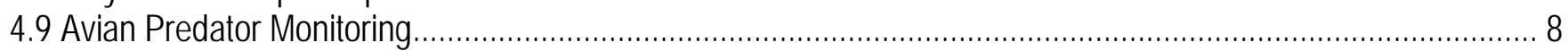

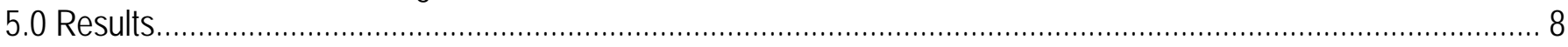

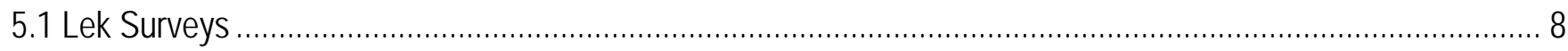

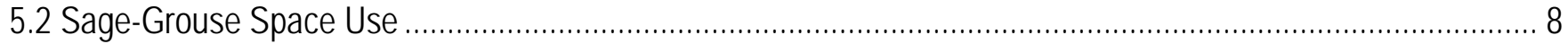

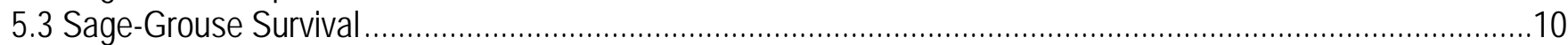

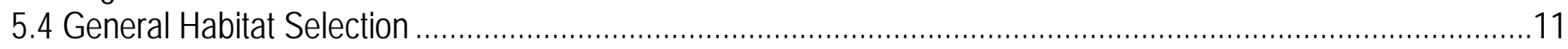

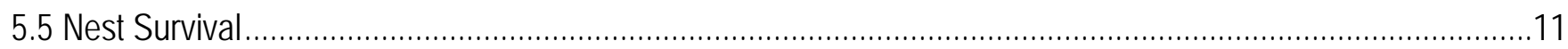

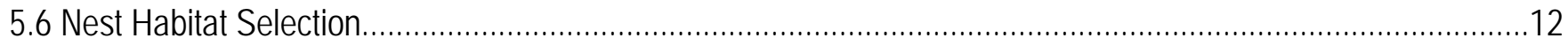

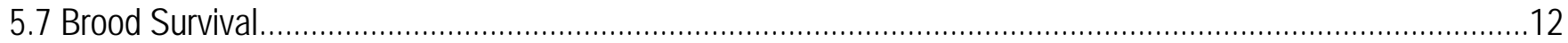

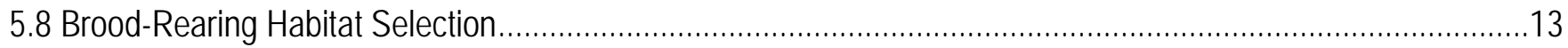

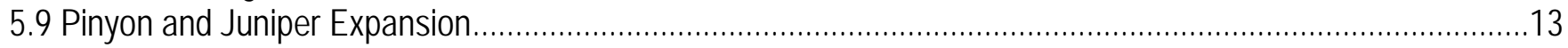

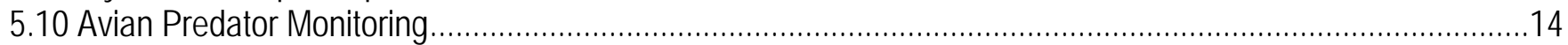

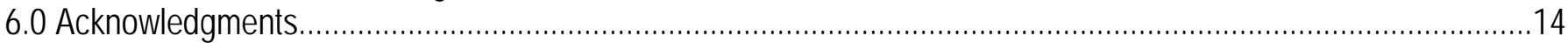

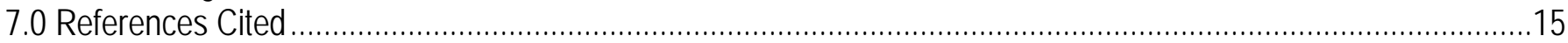

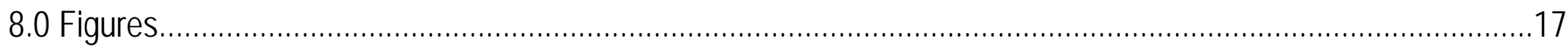

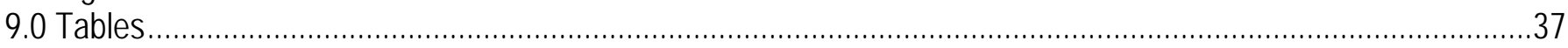

10.0 Appendix A. Evaluation of Bi-State Sage-Grouse Nest Survival Models That Consist of Habitat Characteristic

Covariates for the Pine Nut Mountains, Nevada, 2011-13 


\section{Figures}

Figure 1. Map showing Bi-State Population Management Units (PMU), and Mill Canyon lek in the Pine Nut Mountains study area, Nevada and California, 2011-15

Figure 2. Map showing utilization distribution (March-August) for Bi-State sage-grouse in the northern Pine Nut Mountains, Nevada, 2011-15.

Figure 3. Map showing utilization distribution (March-August) for Bi-State sage-grouse in the southern Pine Nut Mountains, Nevada, 2011-15

Figure 4. Map showing Very High Frequency (VHF) radio-telemetry locations of Bi-State sage-grouse by month (April-August) monitored in the Pine Nut Mountains, Nevada, 2011-15

Figure 5. Map showing Global Positioning System-transmitter locations of Bi-State sage-grouse by month (March-August) monitored in the Pine Nut Mountains and vicinity, Nevada and California, 2012-15.

Figure 6. Map showing Global Positioning System-transmitter locations of Bi-State sage-grouse by month (September-February) monitored in the Pine Nut Mountains and vicinity, Nevada and California, 2012-15

Figure 7. Graph showing number of Global Positioning System locations by month for Bi-State sage-grouse in the Pine Nut Mountains and vicinity, Nevada and California, 2012-15...

Figure 8. Graph showing cumulative average annual adult survival probabilities for Bi-State sage-grouse

in the Pine Nut Mountains, Nevada and California, 2011-15

Figure 9. Map showing lek location, mortality, nest (2011-14) and brood and general telemetry locations (2011-15) for Bi-State sage-grouse in the Pine Nut Mountains, Nevada

Figure 10. Graph showing average percent cover ( \pm standard error) of perennial forbs at general telemetry locations (Used) and dependent random (DR) and independent random (IR) locations in the Pine Nut Mountains, Nevada, 2011-14

Figure 11. Graph showing average percent cover ( \pm standard error) at 0-degree and 45-degree angles (horizontal cover), and at 90-degree angle (vertical cover) for general telemetry locations (Used) and dependent random (DR) and independent random (IR) locations in the Pine Nut Mountains, Nevada, 2011-14 ....... 25 Figure 12. Map showing nest locations and nest fate for Bi-State sage-grouse in the Pine Nut Mountains, Nevada, 2011-14

Figure 13. Graph showing cumulative nest survival probability for Bi-State sage-grouse over the 37-day egg-laying and incubation period in the Pine Nut Mountains, Nevada, 2011-15.

Figure 14. Graph showing cumulative nest survival probability for Bi-State sage-grouse in relation to big sagebrush cover in the Pine Nut Mountains, Nevada, 2011-13.

Figure 15. Graph showing average percent shrub cover ( \pm standard error) at Bi-State sage-grouse nest (Used) locations and dependent random (DR) and independent random (IR) locations in the Pine Nut Mountains, Nevada, 2011-14

Figure 16. Graph showing average height ( \pm standard error) of sagebrush at Bi-State sage-grouse (Used) locations and dependent random (DR) and independent random (IR) locations in the Pine Nut Mountains, Nevada, 2011-14.

Figure 17. Graph showing average percent cover ( \pm standard error) of perennial grasses at Bi-State sage-grouse nest (Used) locations and dependent random (DR) and independent random (IR) locations in the Pine Nut Mountains, Nevada, 2011-14

Figure 18. Graph showing average percent horizontal and vertical cover ( \pm standard error) at Bi-State sage-grouse nest (Used) locations and dependent random (DR) and independent random (IR) locations in the Pine Nut Mountains, Nevada, 2011-14

Figure 19. Graphs showing average percent sagebrush and non-sagebrush cover ( \pm standard error) at Bi-State sage-grouse nest (Used) locations and dependent random (DR) and independent random (IR) locations in the Pine Nut Mountains, Nevada, 2011-14 
Figure 20. Graph showing cumulative survival probability for the 50-day brood-rearing phase across age of brood in the Pine Nut Mountains, Nevada, 2011-14.

Figure 21. Graph showing average horizontal and vertical vegetation cover ( \pm standard error) at day and night brood-rearing locations and dependent random (DR) locations (based of used day location) in the Pine Nut Mountains, Nevada, 2011-14.....

Figure 22. Graphs showing average height ( \pm standard error) of sagebrush and non-sagebrush shrub species at day and night brood-rearing locations and dependent random (DR) locations (based on used day location) in the Pine Nut Mountains, Nevada, 2011-14

Figure 23. Graph showing average percent cover of sagebrush ( \pm standard error) at day and night brood-rearing locations and dependent random (DR) locations (based on used day location) in the Pine Nut Mountains, Nevada, 2011-14.....

Figure 24. Graph showing average percent of perennial forb cover ( \pm standard error) at day and night brood-rearing locations and dependent random (DR) locations (based on used day location) in the Pine Nut Mountains, Nevada, 2011-14

Figure 25. Graph showing average distance ( \pm standard error) from day and night brood locations and at dependent random (DR) and independent random (IR) locations to nearest pinyon and juniper trees in the Pine Nut Mountains, Nevada, 2011-13

Figure 26. Graph showing average distance ( \pm standard error) from general telemetry locations and dependent random (DR) and independent random (IR) locations to pinyon and juniper trees to in the Pine Nut Mountains, Nevada, 2011-14

Figure 27. Graph showing average distance ( \pm standard error) from day and night general telemetry locations and dependent random (DR) and independent random (IR) locations to pinyon and juniper trees in the Pine Nut Mountains, Nevada, 2012

Figure 28. Graph showing average distance ( \pm standard error) from nest locations and to dependent random (DR) and independent random (IR) locations to pinyon and juniper trees to in the Pine Nut Mountains, Nevada, 2012-14

Figure 29. Map showing locations of 592 avian predator surveys and number of ravens detected during April-July in the Pine Nut Mountains, Nevada, 2011-14

\section{Tables}

Table 1. Nest habitat selection at used nest locations, and dependent random (DR) and independent random (IR) locations in the Pine Nut Mountains, Nevada, 2011-14

Table 2. Percent of all sagebrush cover and non-sagebrush cover at used nest locations, and dependent random (DR) and independent random (IR) locations in the Pine Nut Mountains, Nevada, 2011-14

Table 3. Brood habitat selection at used locations, and dependent random (DR) and independent random (IR) locations in the Pine Nut Mountains, Nevada, 2011-14 


\section{Conversion Factors}

SI to Inch/Pound

\begin{tabular}{lll}
\hline \multicolumn{1}{c}{ Multiply } & By & \multicolumn{1}{c}{ To obtain } \\
\hline centimeter (cm) & Length & \\
meter (m) & 0.3937 & inch (in.) \\
kilometer $(\mathrm{km})$ & 3.281 & foot (ft) \\
\hline & 0.6214 & mile (mi) \\
\hline square meter $\left(\mathrm{m}^{2}\right)$ & Area & \\
hectare (ha) & 0.0002471 & acre \\
\hline & 2.471 & acre \\
\hline kilogram (kg) & Mass & \\
\hline
\end{tabular}

\section{Datums}

Vertical coordinate information is referenced to the North American Vertical Datum of 1988 (NAVD 88).

Horizontal coordinate information is referenced to the North American Datum of 1983 (NAD 83).

\section{Acronyms and Abbreviations}

USGS, U.S. Geological Survey

GPS, Global Positions System

DPS, Distinct Population Segment

PMU, Population Management Unit

P-J, pinyon and juniper

VHF, Very High Frequency

PTT, Platform Transmitter Terminal

UD, utilization distribution

$\mathrm{Cl}$, confidence interval 


\title{
Monitoring and Research on the Bi-State Distinct Population Segment of Greater Sage-Grouse (Centrocercus urophasianus) in the Pine Nut Mountains, California and Nevada-Study Progress Report, 2011-15
}

\author{
By Peter S. Coates ${ }^{1}$, Katie M. Andrleㄹ, Pilar T. Ziegler², and Michael L. Casazza1
}

\subsection{Abstract}

The Bi-State distinct population segment (DPS) of greater sage-grouse (Centrocercus urophasianus) that occurs along the Nevada-California border was proposed for listing as threatened under the Endangered Species Act (ESA) by the U.S. Fish and Wildlife Service (FWS) in October 2013. However, in April 2015, the FWS determined that the Bi-State DPS no longer required protection under the ESA and withdrew the proposed rule to list the Bi-State DPS (U.S. Fish and Wildlife Service, 2015). The Bi-State DPS occupies portions of Alpine, Mono, and Inyo Counties in California, and Douglas, Esmeralda, Lyon, Carson City, and Mineral Counties in Nevada. Unique threats facing this population include geographic isolation, expansion of single-leaf pinyon (Pinus monophylla) and Utah juniper (Juniperus osteosperma), anthropogenic activities, and recent changes in predator communities. Estimating population vital rates, identifying seasonal habitat, quantifying threats, and identifying movement patterns are important first steps in developing effective sage-grouse management and conservation plans. During 2011-15, we radio- and Global Positioning System (GPS)-marked (2012-14 only) 44, 47, 17, 9, and 3 sage-grouse, respectively, for a total of 120, in the Pine Nut Mountains Population Management Unit (PMU). No change in lek attendance was detected at Mill Canyon (maximum=18 males) between 2011 and 2012; however, 1 male was observed in 2014 and no males were observed in 2013 and 2015. Males were observed near Bald Mountain in 2013, making it the first year this lek was observed to be active during the study period. Males were observed at a new site in the Buckskin Range in 2014 during trapping efforts and again observed during surveys in 2015. Findings indicate that pinyon-juniper is avoided by sage-grouse during every life stage. Nesting females selected increased sagebrush cover, sagebrush height, and understory horizontal cover, and brood-rearing females selected similar areas, but also preferred increased perennial forb abundance. Using maximum likelihood estimation, nest survival for the Pine Nut Mountains PMU during 2011-14 was 23.8 percent (95-percent confidence interval [CI] $=0.3-40.6$ percent) and appeared lower in comparison to the average 42 percent nest success for sage-grouse range-wide.

\footnotetext{
${ }^{1}$ U.S. Geological Survey.

${ }^{2}$ Bureau of Land Management.
} 
Brood survival for 50-day brood-rearing phase in the Pine Nut Mountains PMU during 2011-14 was 53.8 percent (95-percent $\mathrm{CI}=30.0-73.4$ percent). Adult survival during 2011-15 was 67.4 percent (95percent CI=56.1-76.5 percent). During 2011-14, 696 raptor/raven surveys were completed and results indicate a greater number of raven detections $(n=464)$ in the Pine Nut Mountains PMU than at other study areas in Nevada. These data will be used to develop a predator index. We conducted a more minimal monitoring effort of sage-grouse populations during the 2015 field season, which included trapping efforts, general telemetry, brood monitoring, and GPS monitoring. Nest monitoring, microhabitat sampling, and raptor/raven surveys were not conducted in the 2015 season. Deployment of GPS transmitters has expanded our knowledge of movement corridors and fine-scale movement patterns by sage-grouse in the Pine Nut Mountains PMU. Movement corridors between seasonal habitats were identified with one sage-grouse traveling greater than 100 kilometers south to the Bodie Mountains in California for the winter season. The use of GPS technology to monitor movements in conjunction with intensive field efforts will be important in developing habitat models and maps for the Pine Nut Mountains PMU.

\subsection{Background}

Greater sage-grouse (Centrocercus urophasianus, hereinafter referred to as "sage-grouse”) distribution has decreased range-wide and populations have decreased substantially throughout Western North America (Connelly and others, 2004). The Bi-State distinct population segment (DPS) is genetically distinct (Benedict and others, 2003; Oyler-McCance and others, 2005) and was proposed for listing as a threatened species by the U.S. Fish and Wildlife Service (FWS), but the FWS recently withdrew the proposed rule for listing (U.S. Fish and Wildlife Services, 2015). Recent studies indicate that the Bi-State DPS may require different vegetation types to meet seasonal requirements than populations in other portions of sage-grouse range (Kolada, Casazza, and Sedinger, 2009; Kolada, Sedinger, and Casazza, 2009).

The Pine Nut Mountains are in Lyon and Douglas Counties, Nevada, and are at the northernmost end of the Bi-State DPS range. A small, isolated population of Bi-State sage-grouse occupies the Pine Nut Mountains. Population numbers in the Pine Nut Mountains Population Management Unit (PMU) are thought to be very low, and sage-grouse habitat in this unit is highly fragmented, mostly because of extensive encroachment of single-leaf pinyon (Pinus monophylla) and Utah juniper (Juniperus osteosperma, hereinafter referred to as P-J) into the sagebrush ecosystem. Large-scale landscape changes in the Pine Nut Mountains have reduced the available habitat for sage-grouse and potentially have limited access to seasonal use areas. The loss of large, contiguous habitat range-wide (Connelly and others, 2004), coupled with changes in predator communities at local scales (Coates and Delehanty, 2010), have been shown to adversely affect sage-grouse population vital rates. Prior to this study, information was lacking on movement patterns, seasonal habitat use, population vital rates, and factors that threaten Bi-State sage-grouse in the Pine Nut Mountains. In response, the U.S. Geological Survey (USGS) collaborated with the Bureau of Land Management (BLM), Nevada Department of Wildlife (NDOW), and FWS to conduct an intensive investigation of the sage-grouse in the Pine Nut Mountains PMU. 
The long-term objectives of this study are to

1. Develop an effective collaboration between land and wildlife administrators and research agencies to improve our knowledge of Bi-State sage-grouse populations in the northern part of the Bi-State area,

2. Identify patterns of sage-grouse habitat selection at multiple spatial scales,

3. Estimate population vital rates,

4. Monitor lek attendance,

5. Identify seasonal and annual movement patterns and calculate utilization distributions,

6. Estimate the effects of P-J encroachment on sage-grouse populations,

7. Identify impacts from avian predators on survival rates and develop a raptor/raven predator index, and

8. Develop a spatially explicit map of sage-grouse habitat to better inform forthcoming decisions by land managers.

This report presents findings from the first 5 years of study of an ongoing long-term research effort. However, the findings contained in this report are to be interpreted with caution and some findings (as indicated in the body of the report) should be considered only as preliminary because they are based on limited sample sizes and will be updated annually. Conclusive relationships regarding demographics and factors that influence vital rates will be estimated after further rigorous statistical analyses and are not presented in this report.

\subsection{Study Area}

The Pine Nut Mountains study area is topographically diverse and encompasses 232,695 ha (BiState Local Planning Group, 2004) of the Bi-State area. Dominant plant communities consist of sagebrush-steppe (Artemisia spp.) and mixed mountain shrub communities with extensive single-leaf pinyon and Utah juniper woodlands throughout the study area. Overstory of sagebrush communities is characterized by big sagebrush (Artemisia tridentata spp.) and dwarf sagebrush (Artemisia arbuscula spp). Other shrub cover consists of a variety of rabbitbrush (Chrysothamnus and Ericameria spp.), Bailey's greasewood (Sarcobatus baileyi), and horsebrush (Tetradymia spp.). Overstory of mountain shrub communities is characterized by big sagebrush and a variety of mountain shrubs, including Utah serviceberry (Amelanchier utahensis), common snowberry (Symphoricarpos albus), and desert bitterbrush (Purshia glandulosa). Dominant forbs consist of wooly mule-ears (Wyethia mollis), lupine (Lupinus spp.), and arrowleaf balsamroot (Balsamorhiza sagittata). Grasses include bluebunch wheatgrass (Pseudoroegneria spicata), crested wheatgrass (Agropyron cristatum), Great Basin wild rye (Elymus cinereus), needle-and-thread grass (Hesperostipa comata) and Indian ricegrass (Achnatherum hymenoides). 


\subsection{Methods}

\subsection{Lek Surveys}

Lek counts were conducted according to standard USGS lek survey protocol (U.S. Geological Survey, 2015). When the study began, the Mill Canyon lek was the only confirmed lek active in the study area. This lek was counted at least four times each spring (March-May). The four counts were equally spaced in time and overlapped with peak male attendance. Lek counts were conducted between 30 minutes before sunrise and 90 minutes after sunrise. Binoculars, a spotting scope, or both were used to count sage-grouse from a suitable viewing location that afforded a view of the entire lek. A total of three counts were conducted at 10-minute intervals, and the highest count for three separate categories (male, female, unknown) was selected for each survey. Additionally, leks were searched for in the Buckskin Range, and near Bald and Eagle Mountains in the southern part of the Pine Nut Mountains.

\subsection{Capturing and Handling Sage-Grouse}

We captured and handled sage-grouse in accordance with WERC Animal Care and Use Protocol WERC-2015-02 (Sue Jones, U.S. Geological Survey, written commun., 2016). For each study year, sage-grouse were captured during the spring (March-May), summer (June-July), and autumn (AugustOctober). Sage-grouse were located after sunset and before sunrise with spotlights and were captured with long-handled nets and hand-held net launching devices (SuperTalon ${ }^{\circledR}$, Advanced Weapons Technology, La Quinta, California). Sage-grouse were fitted with battery powered, necklace-style Very High Frequency (VHF) transmitters (<3 percent body mass, 1-1.8 kg, Advanced Telemetry Systems, Isanti, Minnesota) that were equipped with mortality sensors. During 2012-14, a subsample of sagegrouse was outfitted with a Global Positioning System (GPS), Platform Transmitter Terminal (PTT; <3 percent body mass, North Star Science and Technology, LLC, King George, Virginia) and a VHF radio. The purpose of the GPS transmitter was to collect locations remotely and to transmit (using PTT) to a central database by satellites. The purpose of the VHF attachment to the GPS-PTT was to relocate the sage-grouse in the field and to retrieve GPS-PTT devices that no longer transmitted.

Captured sage-grouse were weighed and multiple morphometric measurements, including tarsus and culmen, were recorded to calculate a body-condition index. Blood was extracted from the brachial vein for genetic analyses (mitochondrial and nuclear microsatellite). These genetic data will be used to identify genetic variation and divergence compared to other sage-grouse populations. Age classification was based on plumage characteristics of the 9th and 10th primaries (Ammann, 1944). Sage-grouse were classified as juvenile (pre-breeding), yearling (first year breeding), or adult ( $>1$ breeding year). Plumage photographs (extended wings, rectrices, breast, and head profile) were taken for each sage-grouse. Sagegrouse were processed within 30 minutes of capture and released at their capture location.

\subsection{Monitoring Sage-Grouse}

\subsubsection{Radio and GPS Telemetry}

We conducted intensive on-the-ground monitoring of sage-grouse movement, survivorship, and reproduction following release of marked birds during the spring. All telemetry procedures were conducted according to the USGS sage-grouse telemetry protocol (U.S. Geological Survey, 2015) for VHF transmitters. A three-element Yagi antenna (Advanced Telemetry Systems, Inc., Isanti, Minnesota) and portable receiver (Communications Specialists, Inc., Orange, California) were used to track radiomarked sage-grouse. Location error was minimized by circling each sage-grouse at a radius of 30-50 m. 
After the location of the bird being tracked was determined, the distance was approximated and the azimuth was recorded from the observer's location (using GPS) to estimate the location coordinates (Universal Transverse Mercator) of the sage-grouse. Throughout the nesting season (March-May), attempts were made to locate both VHF- and GPS-marked female sage-grouse at least twice per week. Brood-rearing females were located on 10-day intervals until the brood reached 50 days post-hatch. For non-nesting or brood-rearing females, general telemetry locations were obtained approximately weekly during the summer season (June-August) to monitor seasonal movements. Aerial fixed-wing telemetry flights were conducted to locate sage-grouse that could not otherwise be located from the ground. Additional flights were conducted after summer field work was completed in July or August to identify autumn and winter use areas and seasonal mortality rates.

\subsubsection{Utilization Distributions}

Estimations were made of utilization distributions (UDs; Kernohan and others, 2001), which interpolate animal space use across unknown areas based on the distribution and density of known location telemetry data (Worton, 1989). These UDs provide useful tools for evaluating sage-grouse space use because they allow for estimation of the total area used by individual birds, while accounting for the imperfect monitoring effort that is common to radio-telemetry studies. To calculate UDs, a kernel density estimator was used with a likelihood-based technique to estimate the most appropriate smoothing parameter (Horne and Garton, 2006). UDs were calculated at the population level for spring through summer (March-August) for the northern and southern parts of the study area. UDs were not calculated for each individual because of limitations in relocations per individual during the spring period. The regional core use area was defined as the 50-percent contour (isopleth) from the UD, and the home-range was defined as the 95-percent contour.

\subsection{Nest Survival}

Nest sites were identified for radio-marked (VHF and GPS) sage-grouse according to USGSestablished protocols (U.S. Geological Survey, 2015). Nests were verified visually after hens were found in the same location on two consecutive observations. Each nest was then monitored three times or more per week until the fate of the nest was determined. A nest was considered successful if one or more chicks hatched, as determined by visual assessment of eggshell remains or observing one or more chicks in the nest bowl. Nests were considered unsuccessful when the entire clutch failed to hatch. Failed nests were scored as depredated, partially depredated (one or more intact egg), or abandoned.

The maximum likelihood estimation approach was used to estimate daily and cumulative nest survival probabilities and modeled survival as a function of nest-specific habitat characteristics. An encounter history of individual nests was developed, based on the date each nest was found, last checked, and the fate determined, and this history was coupled with habitat characteristics as explanatory variables (White and Burnham, 1999). The effects of nest-level habitat characteristics, both linear and quadratic, were estimated as additive terms in the models and the improvement over a null model (intercept-only, no covariates) was evaluated using Akaike’s Information Criterion (Anderson, 2008). Model parameters for nest survival in Program $R$ were estimated using the software package, "RMark” (Laake and Rexstad, 2008). 


\subsection{Nest Site Microhabitat}

We closely followed USGS protocol for measuring nest vegetation variables in the field (U.S. Geological Survey, 2015). Following nest success or failure, understory cover at the nest bowl was recorded using a cover board technique (modified from Jones, 1968). Measurements were taken $2 \mathrm{~m}$ from the board at 0-, 45-, and 90-degree $\left(^{\circ}\right)$ angles from the board. Board direction from the nest bowl was randomly assigned for the first set of measurements, and a total of three measurement sets were taken, with each separated by a $120^{\circ}$ rotation of the cover board. Horizontal cover was measured using the 0 and $45^{\circ}$ angle measurements (Jones, 1968; Ritchie and others, 1994). Vertical cover was measured using the $90^{\circ}$ measurement, and total cover was measured using all three angles combined. Vegetation composition cover also was measured at multiple subplots $(20 \times 50 \mathrm{~cm})$ less than or equal to $25 \mathrm{~m}$ from each nest using the Daubenmire method (Daubenmire, 1959). Canopy cover was measured using the line intercept method (Canfield, 1941), along two 25-m transects, one 50-m transect, and one 100-m transect extending from the nest bowl. Orientation of the first transect was randomly assigned and the remaining three transects were sequentially oriented at $90^{\circ}$ intervals to the previous transect. Shrub species, crown width $(\mathrm{cm})$, and height $(\mathrm{cm})$ of a random sample of individual shrubs along the intercept line were recorded to quantify shrub cover. Measurements were recorded within 5, 10, and $25 \mathrm{~m}$ of the nest for all four transect lines, within $50 \mathrm{~m}$ for two transect lines and $100 \mathrm{~m}$ for one transect line. The purpose of the different transect lengths was to identify the spatial scale of use for shrub cover within a 100-m radius of the nest. In 2014, we refined the nest habitat sampling design to include only three 25$\mathrm{m}$ transects and did not measure shrub canopy cover at the 50 and $100 \mathrm{~m}$ spatial scales.

To examine nest site habitat selection, defined as use disproportionate to availability (Manly and others, 2002), means and confidence intervals of the vegetation measurements at nest sites were compared with those at random locations. To characterize available vegetation, we generated random locations throughout the study area and completed the same habitat survey methods at those locations centered at the nearest shrub. Evidence for multi-scale selection was evaluated by generating two random locations for each nest (used, U). One point was within $500 \mathrm{~m}$ of the nest (dependent random, DR) and the other point was within the boundaries of the study area (independent random, IR). The boundary of the study area was established using a minimum convex polygon from all used locations. This design has two advantages: (1) inferences can be made about sage-grouse habitat selection at the individual level by comparing the used locations to dependent random locations, and (2) inferences can be made at the population level by comparing the used locations to the independent random locations. Results are reported as means ( \pm standard error) of vegetation characteristics for nest sites and random locations. This study is ongoing and results should be interpreted with caution. A robust modeling approach will be used after obtaining appropriate sample sizes ( $\geq 3$ years of data). 


\subsection{Brood Survival}

Following the completion of a successful nest, female radio-marked sage-grouse with broods were monitored every 10 days at day and night locations for up to 50 days. During day location surveys, the number of surviving chicks in the brood was counted. To confirm unsuccessful broods and to prevent false negative values, an additional search for chicks was conducted within 48 hours of finding females without broods. A brood was considered successful if one or more chicks survived to 50 days post-hatch. Results are reported by estimating brood survival probabilities across a 50-day period using maximum likelihood estimation. With additional data from subsequent years of study, we will conduct a more intensive investigation of survival covariates. Results include estimated survival probabilities for a 10-day interval and cumulative across the 50-day period. Model parameters were estimated for brood survival in Program R (R Development Core Team, 2008) using the software package, "RMark" (Laake and Rexstad, 2008).

\subsection{Brood-Rearing Microhabitat}

Microhabitat surveys were completed at each brood location every 10 days. Surveys were conducted at day, night, and random locations. To accurately relocate a site where a brood was observed, the telemetry point was recorded by GPS, and a photograph was taken of the immediate area. Habitat measurements similar to those taken at nests were taken at brood locations. However, the maximum extent for a transect line at brood locations was $25 \mathrm{~m}$. Canopy cover was measured along three $25-\mathrm{m}$ transects extending from the brood location every $120^{\circ}$ with random orientation. The crown width $(\mathrm{cm})$ and height $(\mathrm{cm})$ of each shrub species were measured along the three transect lines within 5 , 10 , and $25 \mathrm{~m}$ of the brood location. Vegetation measurements were taken at 10-day intervals to evaluate vegetation change in relation to brood location through time. Differences in habitat use between night (roosting) and day (foraging) locations also were evaluated. To characterize available habitat, the same habitat measurements were conducted at dependent random locations within $500 \mathrm{~m}$ of each day location. Independent locations were not used because these areas arguably are not accessible to broods because of limitations in movement of the flightless chicks.

\subsection{Pinyon and Juniper Expansion}

The abundance and structure of P-J near nest and brood sites were measured to assess the larger role of P-J expansion on sage-grouse distribution and productivity. Surveys were conducted for P-J at used and random locations (DR and IR) for nests, broods, and general telemetry locations.

Measurements were recorded at the central point (location of nest, brood, or general telemetry), and at four random locations within $100 \mathrm{~m}$ of the central point in each cardinal direction. For each site, the bearing and distance to the closest P-J present were recorded, as well as the distance from that P-J to the nearest neighboring tree. Each P-J was classified into four height classes (Class 1, 0-1 m; Class 2, 1-2 $\mathrm{m}$; Class 3, 2-3 m; Class 4, >3 m). The closest possible perch that could be used by predatory birds also was recorded and defined as the closest P-J with a perching surface above shrub height (Class 2 or greater). Surveys were conducted during the day and night for general telemetry and brood locations, and during the day only for nest locations. 


\subsection{Avian Predator Monitoring}

USGS predator survey protocol for common raven (Corvus corax) and raptor surveys (U.S. Geological Survey, 2015) was followed during the sage-grouse reproductive season (mid-April and lateJuly). Visual surveys were conducted (using binoculars and unaided eyes) for each nest location from a distance of approximately 50-100 m. Surveys were conducted over a 10-minute period wherein all four directional quadrants around the nest were scanned for an equal amount of time. For each avian predator detected, the time, bearing, and distance from the survey point when first detected (using a rangefinder) were recorded, and all birds were classified to species. Final observations of ravens and raptor species are reported. The time of survey was randomized between 30 minutes before sunrise and 30 minutes after sunset. The same survey technique was implemented at random locations as well. Randomized surveys will be used to estimate raven and raptor densities by habitat type and across the study site using Program Distance (Thomas and others, 2010). We also plan to calculate a raven abundance index from these survey data to evaluate the indices as a covariate to nest survival, as ravens are known predators of sage-grouse eggs and nestlings (Coates and others, 2008; Coates and Delehanty, 2010). These analyses will be conducted after sufficient sample sizes are reached.

\subsection{Results}

\subsection{Lek Surveys}

In 2011, two lek surveys were conducted at the Mill Canyon lek and the high male count was 18 sage-grouse. In 2012, four surveys were conducted and the high male count also was 18. In 2013, three surveys were conducted at Mill Canyon and one survey was conducted at Bald Mountain. No sagegrouse were observed during any of the surveys at Mill Canyon. The high count at Bald Mountain was two males and one bird of undetermined sex. In 2014, four surveys were conducted at Mill Canyon and three surveys were conducted at Bald Mountain. One male was observed displaying at Mill Canyon. The high counts at Bald Mountain were eight males and one female. In the spring of 2014, males were observed displaying in the Buckskin Range during trapping. In 2015, NDOW conducted lek surveys and observed six males and five females at Bald Mountain, two males approximately $1 \mathrm{~km}$ apart in the Buckskin Range, and no birds were observed on Mill Canyon (Carl Lackey, Nevada Department of Wildlife, oral. commun., 2015). However, two sage-grouse of unknown sex were observed approximately $2 \mathrm{~km}$ from the Mill Canyon lek.

\subsection{Sage-Grouse Space Use}

During 2011-15, we radio- and GPS-marked (2012-14 only) 44, 47, 17, 9, and 3 sage-grouse, respectively, for a total of 120 ( $n=28$, male; $n=92$, female; $n=93$, VHF; $n=27$, GPS), in the Pine Nut Mountains Population Management Unit (PMU).

In spring 2015, three sage-grouse ( $n=2$, male; $n=1$, female) were captured and fitted with VHF transmitters. Thirteen sage-grouse ( $n=3$, male; $n=10$, female; $n=7$, VHF; $n=6$, GPS) were monitored throughout spring and summer, including 10 captured in previous years. 
In spring 2014, seven sage-grouse ( $n=2$, male; $n=5$, female) were captured and fitted with VHF $(n=4)$ or GPS-transmitters $(n=3)$. One was a radio-marked female from a previous season that was recaptured and the VHF transmitter was replaced with a new collar. Eighteen sage-grouse ( $n=2$, male; $n=16$, female; $n=9$, VHF; $n=9$, GPS) were monitored throughout spring and summer, including 12 captured in previous years. In autumn, three GPS units were deployed on females.

In spring and summer 2013, eight sage-grouse ( $n=1$, male; $n=7$, female) were captured and fitted with VHF $(n=2)$ or GPS transmitters $(n=6)$. Four of these GPS transmitters replaced VHF collars on recaptured brood-rearing females. Twenty-nine sage-grouse ( $n=5$, male; $n=24$, female; $n=13$, VHF; $n=16$, GPS) were monitored throughout spring and summer, including 25 captured in 2011-12. In autumn, nine sage-grouse ( $n=2$, male; $n=7$, female) were captured and fitted with VHF ( $n=5)$ or GPStransmitters $(n=4)$.

In spring 2012, 16 sage-grouse ( $n=4$, male; $n=12$, female) were captured and fitted with VHF $(n=5)$ or GPS transmitters $(n=11)$. Nine sage-grouse fitted with VHF transmitters from 2011 were recaptured, seven ( $n=1$, male; $n=6$, female) of which had their VHF transmitters removed and replaced with GPS transmitters. Forty-seven sage-grouse ( $n=10$, male; $n=37$, female; $n=32$, VHF; $n=15$, GPS) were monitored throughout spring and summer, including 31 captured in 2011. In autumn, 31 sagegrouse ( $n=5$, male; $n=26$, female), plus 2 previously collared sage-grouse ( $n=1$, male; $n=1$, female) from 2011, were captured and fitted with new VHF transmitters.

In spring 2011, 13 sage-grouse ( $n=7$, male; $n=6$, female) were captured and fitted with VHF transmitters. In autumn, 31 sage-grouse ( $n=5$, male; $n=26$, female) were captured and fitted with VHF transmitters.

Spring through summer (March-August) UDs for sage-grouse were calculated based on movement patterns from the northern Mill Canyon lek area (nesting) to the southern Mount Siegel area (brood rearing) (figs. 2 and 3). Based on the UDs calculated for the 2011-15 telemetry data, this preliminary assessment indicates that the population level home range (95-percent UD) encompassed 2,428 ha for the northern area of the PMU, and 4,198 ha for the southern area of the PMU (figs. 2 and 3). The core area of sage-grouse activity (50-percent UD) was 138 ha for the northern area of the PMU, and 498 ha for the southern area of the PMU (figs. 2 and 3). Most broods moved south following the nesting period, as evidenced by VHF and GPS locations (figs. 4 and 5). In 2012, the distribution of nest locations shifted farther south than during the preceding year, encompassing Mount Siegel as well as the Mill Canyon lek area. Based on these movement patterns, we suspect the existence of a lek in the Mount Siegel area. However, because we have not confirmed a lek near Mount Siegel, only distances to the Mill Canyon lek are discussed here.

During April-August 2011-15, 847 ground telemetry locations (325, 411, 111, 80, and 14, respectively) were collected from 85 VHF-marked grouse (12, 27, 23, 13, and 10, respectively) (fig. 4). Some collared individuals were never located after capture, which accounts for the lower number of monitored sage-grouse reported compared to the 93 VHF marked sage-grouse during 2011-15. During 2012-15, 33,137 GPS locations were collected from 27 sage-grouse. GPS locations during 2012-15 were delineated into spring through summer (March-August, fig. 5), and autumn through winter (September-February, fig. 6). The number of GPS locations per month steadily decreased as the months progressed (fig. 7), which is thought to be a function of lower charging power because of decreased photoperiod. Additionally, the number of GPS marked sage-grouse decreased as transmitters were removed from the field (for example, mortality and transmitter slips). 
Across the spring and summer seasons of 2011-13, average VHF and GPS locations were within $26.2 \mathrm{~km} \pm 0.13$ of the Mill Canyon lek. The distance between sage-grouse locations and the lek varied substantially among months. In April, 2,741 locations (2011-13) were collected, with an average distance to the lek of $3.4 \mathrm{~km} \pm 0.1 \mathrm{~km}$. In May, a total of 6,896 locations (2011-13) were collected with an average distance to the lek of $17.1 \mathrm{~km} \pm 0.1 \mathrm{~km}$. A total of 6,129 locations were collected during June 2011-13. A few birds continued to use the hills and ridges near the lek, however, by late-June, most sage-grouse moved from the northern Mill Canyon area in a southerly direction to the Mount Siegel area and beyond (figs. 4 and 5). Average distance to the lek for June was $38.7 \pm 0.35 \mathrm{~km}$, which was a substantial increase in distance compared to May locations. Distances are not given for 2014-15 as collaring efforts shifted from Mill Canyon to Bald Mountain and the Buckskin Range.

During summer, sage-grouse congregated in the Mount Siegel and Bald Mountain areas, and some traveled relatively long distances to late summer and autumn habitat outside the Pine Nut Mountains PMU. For example, by the end of June 2012, one GPS-marked adult female captured at the Mill Canyon lek had traveled $90.5 \mathrm{~km}$ to the Sweetwater Mountains in Mono County, California. This female was later observed in the Bodie Hills in Mono County, California (>100 km from Mill Canyon lek) during the autumn, representing the longest travel distance documented to date for a sage-grouse in the Bi-State Area. This individual moved back to the Sweetwater Valley during winter and died January 2013. During July 2011-13, the average distance to the lek was $45.4 \pm 0.3 \mathrm{~km}(n=3,230)$. Seasonal migration patterns appeared to slow during this time, and movements remained concentrated through August. By the end of July, one GPS-marked adult male sage-grouse reached Slinkard Valley in Mono County, California (72.1 km from Mill Canyon lek), and died shortly thereafter (fig. 5). During the first week of August 2011, 18 VHF locations were collected and birds were observed at an average distance of $41.5 \pm 1.4 \mathrm{~km}$ from the lek.

\subsection{Sage-Grouse Survival}

Cumulative average annual adult survival probability during 2011-15 was 67.4 percent (95percent CI = 56.1-76.5 percent; fig. 8). Carcass remains were used to infer the cause of mortality; however, carcasses are often scavenged, thus obscuring evidence of the initial predator. During the summer of 2015, three GPS transmitters were recovered from female sage-grouse in the Pine Nuts. No remains were found and cause of mortality is unknown. In 2014, we recovered three mortalities from GPS marked sage-grouse. Two mortalities ( $n=1$, male; $n=1$, female) occurred during the field season and cause of death appeared to be predation. The third GPS on a female was picked up during autumn with torn straps and bite marks, also indicating predation. During 2013, 20 grouse $(n=3$, male; $n=17$ female) mortalities were confirmed (fig. 9). Assumed causes of death included avian predation $(n=4)$, mammalian predation $(n=4)$, unknown predation $(n=5)$, and unknown cause of mortality $(n=7)$.

During 2012, 19 birds ( $n=7$, male; $n=12$, female; $n=10$, VHF; $n=9$, GPS) were found dead, and one unmarked bird was found dead incidentally. Four mortalities appeared to be caused by mammalian predators and seven mortalities appeared to be caused by avian predators. The remaining mortalities could not be assigned to either predator due to lack of remains.

In 2011, two VHF-marked sage-grouse were found dead during the field season. One mortality appeared to be caused by an avian predator and one appeared to be caused by an unknown predator. 


\subsection{General Habitat Selection}

A total of 631 microhabitat surveys were conducted at used and random locations throughout spring, summer, and autumn 2011-14 to evaluate sage-grouse habitat selection at nest, brood, and general telemetry locations. Of these, 94 surveys were conducted to evaluate nest habitat; 247 surveys were conducted to evaluate brood-rearing habitat; and 290 surveys were conducted to evaluate habitat at general telemetry locations.

Final results from 2011 to 2014 indicate that sage-grouse selected areas with greater perennial forb cover than other nearby areas (DR locations), as well as areas throughout the study area (IR locations) (fig. 10). Additionally, evidence suggests that sage-grouse selected areas with significantly more horizontal and vertical vegetation cover (Horizontal [U]=59.0 \pm 2.8 percent; Vertical [U] $=42.6$ \pm 3.7 percent) than other nearby areas (Horizontal [DR] $=44.4 \pm 3.0$ percent; Vertical [DR] $=24.4 \pm 3.3$ percent) and across the study area (Horizontal [IR] $=50.2 \pm 3.0$ percent; Vertical [IR] $=30.7 \pm 4.0$ percent) (fig. 11).

\subsection{Nest Survival}

A total of 32 nests were located in 2011-14 (3, 15, 9, and 5, respectively). Of these, 14 nests were successful and 18 nests failed (figs. 9 and 12). Of the 14 successful nests, 4 were in the Mill Canyon area, 3 were in the Buckskin Range, and the remaining 7 were in the Mount Siegel area (fig. 12). Of the 18 nests that failed, 10 were in the Mill Canyon area, 4 were near Bald Mountain, and 4 were in the Buckskin Range. All successful nests identified were located under sagebrush canopy. One re-nesting attempt was observed near Bald Mountain in 2014.

Five nests were located in 2014, of which two were successful and three failed. For most nests located in 2014, whether successful or failed, unhatched eggs remaining in the nest bowls appeared to be unfertilized based on inspection in the field. For both successful nests, one nest in Mill Canyon hatched two eggs, but the remaining five appeared unfertilized; the second nest in the Buckskin Range hatched six of a seven egg clutch. Of the three failed nests, one female in Mill Canyon abandoned a clutch of six unhatched eggs after incubating for approximately 40 days. Both nesting attempts by a female at Bald Mountain failed: two eggs were depredated and the remaining five were left untouched at the first nest, and the second nest was depredated. Nine nests were located in 2013, of which five nests were successful and four failed. Of the four failed nests, one hen was killed, two were depredated, and one was abandoned. Fifteen nests were located in 2012, of which 5 were successful and 10 failed. Of the 10 failed nests, 4 were abandoned. One nest may have been abandoned because of a nearby wildfire (Preacher Fire, $1.2 \mathrm{~km}$ from nest). However, this nest also was parasitized by a chukar (Alectoris chukar). No other nests were affected by the Preacher Fire. Six of the 10 failed nests were confirmed depredated. Nests for four females went undetected because of their extensive movements away from the lek, however, these four females were located with broods during late spring. In 2011, a total of three nests were found, of which two were successful and one failed due to depredation.

The cumulative nest survival probability during 2011-14 for the 37-day egg-laying and incubation phase was 23.8 percent (95-percent $\mathrm{CI}=10.3-40.6$ percent), and daily nest survival probability was 96.2 percent (95-percent $\mathrm{CI}=94.0-97.6$ percent, fig. 13). Based on preliminary findings of single covariate models, nest survival probability increased with greater big sagebrush cover at the 50-m scale (model: Big Sage 50 m; appendix A; fig. 14). Total shrub cover and tall sage cover types (that is, basin and mountain big sagebrush) at the $50-\mathrm{m}$ scale also positively influenced nest survival and were not significantly different from big sagebrush cover. Although we found support for other spatial scales, the 50-m scale showed the greatest evidence in the top models. All top models for canopy cover were linear (appendix A). 


\subsection{Nest Habitat Selection}

We found evidence of selection for several microhabitat variables across all 4 years of data collection. Average percent shrub cover was greater at the nest site, particularly at the nest bowl, than at DR and IR locations (table 1; fig. 15). Sagebrush height was greater at nest sites than at DR and IR locations throughout the study area (table 1; fig. 16). Sagebrush height was greatest at the nest bowl (0 $\mathrm{m})$. We also found greater cover from perennial grasses, on average, at nests and within the nesting vicinity than in areas that were available to sage-grouse throughout the study area (table 1; fig. 17). The results also suggest that sage-grouse selected nest sites with more horizontal and vertical cover than was available near the nests and across the study site (table 1; fig. 18).

The percent of sagebrush canopy cover at nest sites and near nests (DR locations) was similar, and each was greater than the percent of sagebrush cover found across the study area at IR locations at all spatial scales (table 2; fig. 19). At the 10-, 25-, 50-, and 100-m scales, the percent of non-sagebrush cover was greater at IR locations throughout the study site than at or near the nest (table 2; fig. 19). However, we did not find a difference at the 5-m scale. These findings suggest that sage-grouse may select nest sites with greater sagebrush cover than is available in the overall study area, and that they may avoid areas with greater cover from non-sagebrush shrubs.

\subsection{Brood Survival}

The cumulative brood survival probability for 50-day brood-rearing phase (probability of success through the brood-rearing period) was 53.8 percent (95-percent CI=30.0-73.4 percent, fig. 20) for 2011-14. The 10-day interval brood survival probability was 88.8 percent (95-percent CI=78.0-94.0 percent). During 2011-15, 22 broods were followed, of which 10 broods were successful $(2011=2$, 2012 =5, 2013 =2, $2015=1$ ), 8 failed, and 4 were unknown. Two broods were monitored in 2015. One was located in late May with one chick, but the female disappeared before a subsequent check was conducted, and the fate of the brood is unknown. The second was a non-collared female that was trapped during the season with a brood. During the 50-day brood check, one chick was still present. Data from 2015 were not included in the survival analyses due to insufficient monitoring intervals to accurately calculate estimates. There were no successful broods monitored in 2014. For the two successful nests, both females disappeared from the nesting area before the first 10-day brood check and were not located until several weeks later, indicating possible early brood failure. Chicks were not observed during the subsequent monitoring visits for each female; therefore, it was assumed both broods failed before 10 days post-hatch.

In 2012 and 2013, successful broods concentrated near wet meadows in the Mount Siegel and Bald Mountain area on Oreana Peak $(n=2)$ and Bald Mountain $(n=3)$, and wet areas in the Buckskin Range $(n=1)$, and near Rattlesnake Hill $(n=1)$. Sage-grouse roosted on ridges above the meadows during the night and used the perimeter of the meadows during the day. The meadows were small and irregularly shaped, with scattered sagebrush and other shrubs. Seven broods were confirmed successful (one or more chick survived to 50-days post-hatch), three of which were monitored from nest initiation onward. Of the six confirmed unsuccessful broods, four failed at approximately 20 days post-hatch, and two failed at 10 days post-hatch. Three other brood-rearing females were not located after approximately 20, 35, and 40 days post-hatch, respectively.

During 2011, the two successful broods concentrated their movements in areas between Oreana and Galena Peaks. During 2012, the five successful broods, as well as two previously undiscovered broods, concentrated in areas farther south in the Mount Siegel area and used a core area of 150.7 ha. During 2013, three broods located in the northern Mill Canyon area, of which two were successful, used a core area of 192.2 ha. 


\subsection{Brood-Rearing Habitat Selection}

Results for 2011-13 data indicate that brood-rearing sage-grouse used more horizontal and vertical cover during the day than during the night and at DR locations across all spatial scales (table 3; fig. 21). The data indicate that sage-grouse may be avoiding vertical cover at night (fig. 21). At all spatial scales, brood-rearing sage-grouse used locations with taller sagebrush shrubs during the day than at night and at DR locations (table 3; fig. 22). Similarly, the heights of non-sagebrush shrub species at used day locations were significantly greater than shrub heights at used night locations and at DR locations at both the 10 and 25-m spatial scales. Brood location data indicate that sage-grouse may prefer areas with taller stands of shrubs and more horizontal cover during the day.

The amount of canopy cover provided by sagebrush varied between used day, used night, and DR locations. Percent sagebrush cover was consistently greater at used day locations than at night and DR locations across all spatial scales (table 3; fig. 23). These data suggest that brood-rearing sagegrouse are not only selecting daytime locations with more vegetation cover in general, but specifically are selecting greater sagebrush canopy cover and taller stand heights.

Additionally, the average percent of perennial forb cover at brood-rearing locations during the day was greater than at DR locations at all three spatial scales (table 3; fig. 24). Furthermore, day brood locations had significantly greater perennial forb cover than night locations at the 0 - and 25-m spatial scales (table 3; fig. 24).

\subsection{Pinyon and Juniper Expansion}

Nest, brood, and general telemetry locations suggest that sage-grouse avoid areas with P-J. Although the data included all species of trees, living or dead, most trees in the study area were P-J. During 2011-13, brood-rearing sage-grouse located farther from trees during daytime (75.7 $\pm 12.8 \mathrm{~m}$ ) than DR locations (67.8 $\pm 8.6 \mathrm{~m})$; however, these differences are not substantial (fig. 25). Independent random locations were not surveyed during 2012 for the brood-rearing phase because of logistical constraints. However, based on preliminary data from 2011 and 2013, brood-rearing sage-grouse were located farther from P-J during day and night hours (day=75.7 $\pm 12.8 \mathrm{~m}$; night=68.1 $\pm 13.8 \mathrm{~m}$ ) than IR locations (60.6 $\pm 19.0 \mathrm{~m}$ ), suggesting avoidance of P-J at the population level (fig. 25). Although the differences between the used and IR locations were not significant, increased sampling in future study years will more closely approximate population selection or avoidance of P-J.

We found stronger evidence of avoidance of trees from the general telemetry locations during 2011-14. Sage-grouse selected locations that were farther from trees $(155.0 \pm 12.0 \mathrm{~m})$ than available at DR locations (82.3 $\pm 5.1 \mathrm{~m}$ ) and across the study area at IR locations (35.5 $\pm 1.9 \mathrm{~m}$; fig. 26). During 2012, P-J were sampled at used, DR, and IR locations for night observations (excluded from the combined results reported in the above paragraph; fig. 27). In 2012, we observed a strong avoidance of P-J for used night locations (109.8 $\pm 24.8 \mathrm{~m})$, much more so than used day locations (45.5 $\pm 7.8 \mathrm{~m}$; fig. 27). However, day locations were farther from P-J $(50.0 \pm 10.0 \mathrm{~m})$ than locations available at the population level $(23.5 \pm 2.9 \mathrm{~m})$. At night, sage-grouse used locations farther from P-J (109.8 $\pm 24.8 \mathrm{~m})$ than DR locations (48.9 $\pm 11.4 \mathrm{~m}$ ) and IR locations (17.4 $\pm 6.8 \mathrm{~m}$; fig. 27). During 2012-14, P-J surveys were conducted during nest monitoring (fig. 28). Preliminary findings suggest that sage-grouse avoided trees at nest locations $(140.0 \pm 15.8 \mathrm{~m})$ compared to DR $(75.7 \pm 10.4 \mathrm{~m})$ and IR $(40.9 \pm 8.8 \mathrm{~m})$ locations. 


\subsection{Avian Predator Monitoring}

During April-July 2011-14, we conducted 146, 222, 224, and 104 ( $n=696)$ raven and raptor surveys throughout the study site, respectively. A total of 464 raven detections were recorded across all three seasons. A total of 470 raptor detections were recorded, including Turkey Vultures (Cathartes aura) ( $n=199)$, American Kestrels (Falco sparverius) ( $n=81)$, Red-tailed Hawks (Buteo jamaicensis) $(n=86)$, Golden Eagles (Aquila chrysaetos) $(n=66)$, Northern Harriers (Circus cyaneus) ( $n=13)$, and unidentified raptors $(n=23)$. Species with three or fewer detections include Prairie Falcon (Falco mexicanus), Peregrine Falcon (Falco peregrinus), Rough-legged Hawk (Buteo lagopus), Osprey (Pandion haliaetus), and Cooper's hawk (Accipiter cooperii).

Of the total surveys conducted, 323 surveys detected ravens and (or) raptors (46.4 percent), and 166 detected ravens only (23.9 percent). Of the 166 surveys that detected ravens, 63 detected only one raven per survey (38.0 percent), 47 detected two ravens, likely territorial pairs (28.3 percent), and 43 detected between three and six ravens, likely pairs with fledged young (25.9 percent). Four surveys observed more than six ravens $(12,24,66$, and 73 ravens), which likely were large groups of juvenile and (or) unpaired adult birds (fig. 29).

\subsection{Acknowledgments}

We thank M. Shaub and S. Mathews with Idaho State University for outstanding efforts in collecting data in the field for 2 years. We thank the Bureau of Land Management (BLM) for providing logistical support for this research. We extend a special "thank you" to L. Turner with the Nevada Department of Wildlife (NDOW), who provided substantial contributions to this study. We also thank A. Bittner, J. Wilson, S. Brewer, and C. McAlear with the BLM, and C. Lackey, S. Espinosa, and M. Freese with NDOW. We thank Idaho State University field technicians including J. Ragni, Z. Lockyer, M. Novak, M. Mancuso, A. Witchendal, C. Bowman, T. Allen, M. Marshall, N. Dotson, S. Brown, W. Nevins, D. Mackell, A. Merritt, R. Pyles, C. Martin, L. Smith, T. Gettlemen, E. Tobin, P. Kavourlaris, and all volunteers who participated on this project. We also thank E. Blomberg, B. Prochazka, J. Dudko, B. Brussee, S. Murphy, and A. Olson with the USGS who assisted with data analyses. We also thank all members of the Pine Nut Mountains PMU Sage-Grouse Working Group and the many ranching operations in the Pine Nut Mountains for their ongoing support. 


\subsection{References Cited}

Anderson, D.R., 2008, Model based inferences in the life sciences-A primer on evidence: New York, Springer, $184 \mathrm{p}$.

Ammann, G.A., 1944, Determining the age of pinnated and sharp-tailed grouse: Journal of Wildlife Management, v. 8, p. 170-171.

Benedict, N.G., Oyler-McCance, S.J., Taylor, S.E., Braun, C.E., and Quinn, T.W., 2003, Evaluation of the eastern (Centrocercus urophasianus urophasianus) and western (Centrocercus urophasianus phaios) subspecies of sage-grouse using mitochondrial control-region sequence data: Conservation Genetics, v. 4, p. 301-310.

Bi-State Local Planning Group, 2004, Greater sage-grouse conservation plan for the Bi-State Plan Area of Nevada and eastern California_First edition-June 30, 2004: accessed March 4, 2014, at http://www.ndow.org/uploadedFiles/ndoworg/Content/Nevada_Wildlife/Sage_Grouse/Bi-StatePlan.pdf.

Canfield, R.H., 1941, Application of the line intercept method in sampling range vegetation: Journal of Forestry, v. 39, p. 388-394.

Coates, P.S., Connelly, J.W., and Delehanty, D.J., 2008, Predators of greater sage-grouse nests identified by video monitoring: Journal of Field Ornithology, v. 79, p. 421-428.

Coates, P.S., and Delehanty, D.J., 2010, Nest predation of greater sage-grouse in relation to microhabitat factors and predators: Journal of Wildlife Management, v. 74, p. 240-248.

Connelly, J.W., Knick, S.T., Schroeder, M.A., and Stiver, S.J., 2004, Conservation assessment of greater sage-grouse and sagebrush habitats: Cheyenne, Wyoming, Western Association of Fish and Wildlife Agencies, various pagination.

Daubenmire, R., 1959, A canopy-coverage method of vegetational analysis: Northwest Science, v. 33, p. 43-64.

Horne, J.S., and Garton, E.O., 2006, Likelihood cross-validation versus least squares cross-validation for choosing the smoothing parameter in kernel home-range analysis: Journal of Wildlife Management, v. 70, p. 641-648.

Jones, R.E., 1968, A board to measure cover used by prairie grouse: Journal of Wildlife Management, v. 32, p. 28-31.

Kernohan, B.J., Gitzen, R.A., and Millspaugh, J.J., 2001, Analysis of animal space use and movements, in Millspaugh, J.J., and Marzluff, J.M., eds., Radio tracking animal populations: San Diego, Academic Press, p. 125-166.

Kolada, E.J., Casazza, M.L., and Sedinger, J.S., 2009, Ecological factors influencing nest survival of greater sage-grouse in Mono County, California: Journal of Wildlife Management, v. 73, p. 1,341$1,347$.

Kolada, E.J., Sedinger, J.S., and Casazza, M.L., 2009, Nest site selection by greater sage-grouse in Mono County, California: Journal of Wildlife Management, v. 73, p. 1,333-1,340.

Laake, J., and Rexstad, E., 2008, RMark-An alternative to building linear models in MARK, in Cooch, E., and White, G., eds., Program MARK— 'A gentle introduction': Program Mark Web site, accessed March 4, 2014, at http://www.phidot.org/software/mark/docs/book.

Manly, B.F.J., McDonald, L.L., Thomas, D.L., McDonald, T.L., and Erickson, W.P., 2002, Resource selection by animals_-Statistical design and analysis for field studies (2d ed.): Boston, Kluwer Press, $222 \mathrm{p}$.

Oyler-McCance, S.J., Taylor, S.E., and Quinn, T.W., 2005, A multilocus population genetic survey of the greater sage-grouse across their range: Molecular Ecology, v. 14, p. 1,293-1,310. 
R Development Core Team, 2008, R-A language and environment for statistical computing: Vienna, Austria, R Foundation for Statistical Computing, ISBN 3-900051-07-0, accessed March 4, 2014, at http://www.R-project.org.

Ritchie, M.E., Wolfe, M.L., and Danvir, R., 1994, Predation of artificial sage grouse nests in treated and untreated sagebrush: Great Basin Naturalist, v. 54, p. 122-129.

Thomas, L., Buckland, S.T., Rexstad, E.A., Laake, J.L., Strindberg, S., Hedley, S.L., Bishop, J.R.B., Marques, T.A., and Burnham, K.P., 2010, Distance software-Design and analysis of distance sampling surveys for estimating population size: Journal of Applied Ecology, v. 47, p. 5-14.

U.S. Fish and Wildlife Service, 2015, Endangered and threatened wildlife and plants; withdrawal of the proposed rule to list the bi-State distinct population segment of greater sage-grouse and designate critical habita: Federal Register, v. 80, no. 78, p 22827-22866, accessed June 2015, at https://www.federalregister.gov/articles/2015/04/23/2015-09417/endangered-and-threatened-wildlifeand-plants-withdrawal-of-the-proposed-rule-to-list-the-bi-state.

U.S. Geological Survey, 2015, Greater Sage-grouse Project, Nevada-General information and protocols for field operations and monitoring (2015 ed.): U.S. Geological Survey, Western Ecological Research Center, Dixon, California, 83 p., http://www.werc.usgs.gov/ProductDetails.aspx?ID=5422.

White, G.C., and Burnham, K.P., 1999, Program MARK-Survival estimation from populations of marked animals: Bird Study, v. 46, p. 120-139.

Worton, B.J., 1989, Kernel methods for estimating the utilization distribution in home-range studies: Ecology, v. 70, p. 164-168. 


\subsection{Figures}

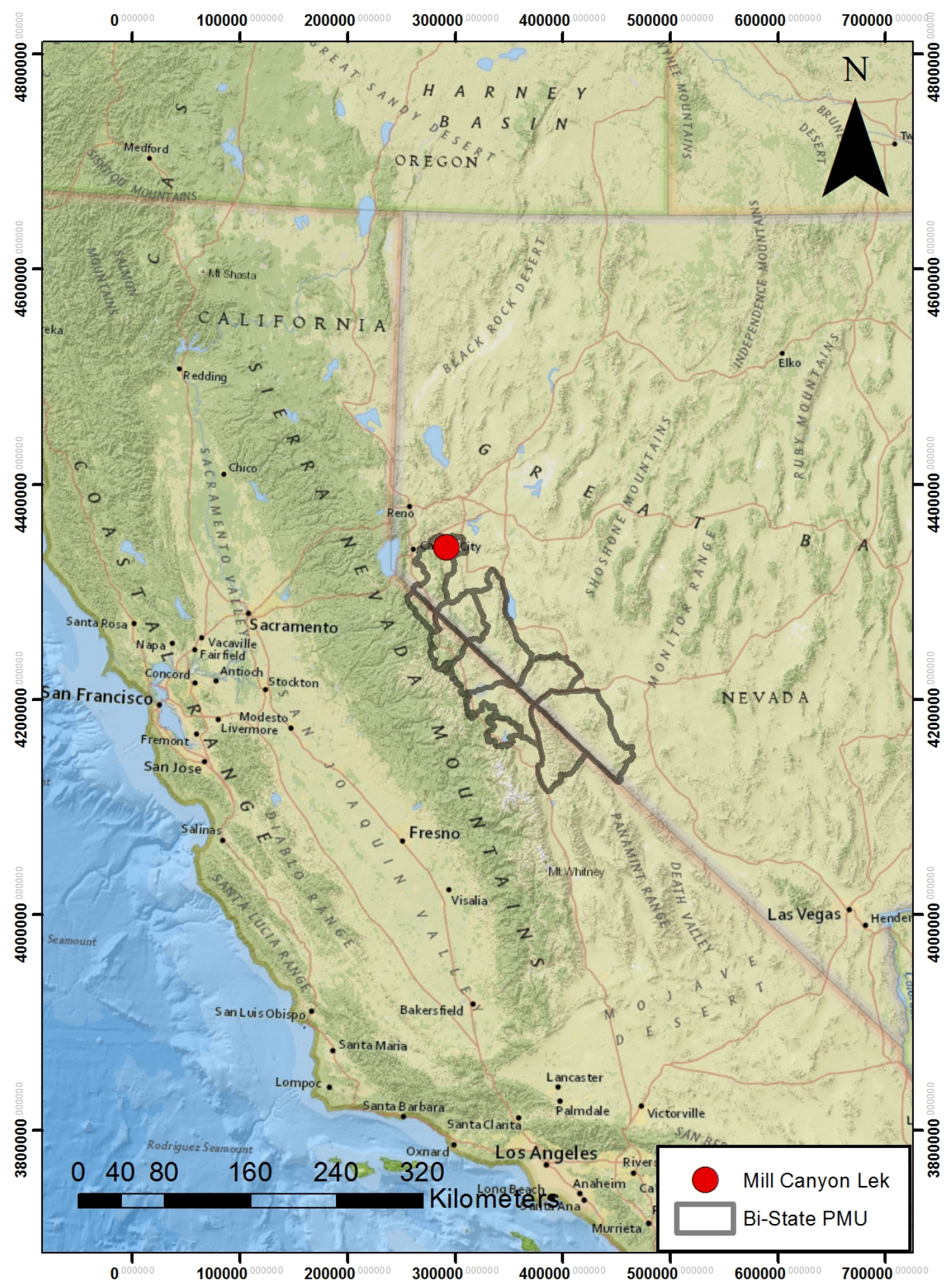

Figure 1. Map showing Bi-State Population Management Units (PMU), and Mill Canyon lek in the Pine Nut Mountains study area, Nevada and California, 2011-15. 


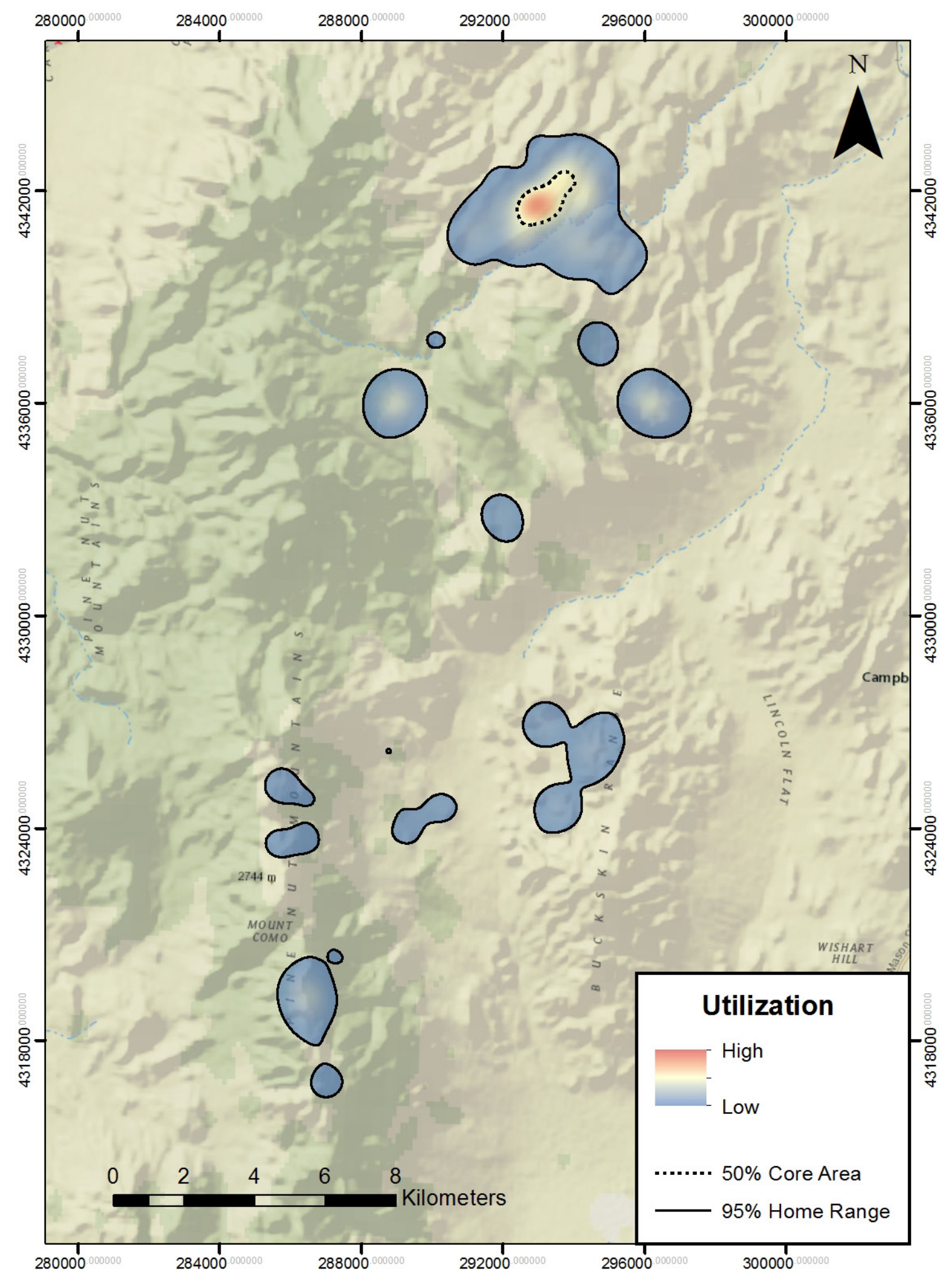

Figure 2. Map showing utilization distribution (March-August) for Bi-State sage-grouse in the northern Pine Nut Mountains, Nevada, 2011-15. 


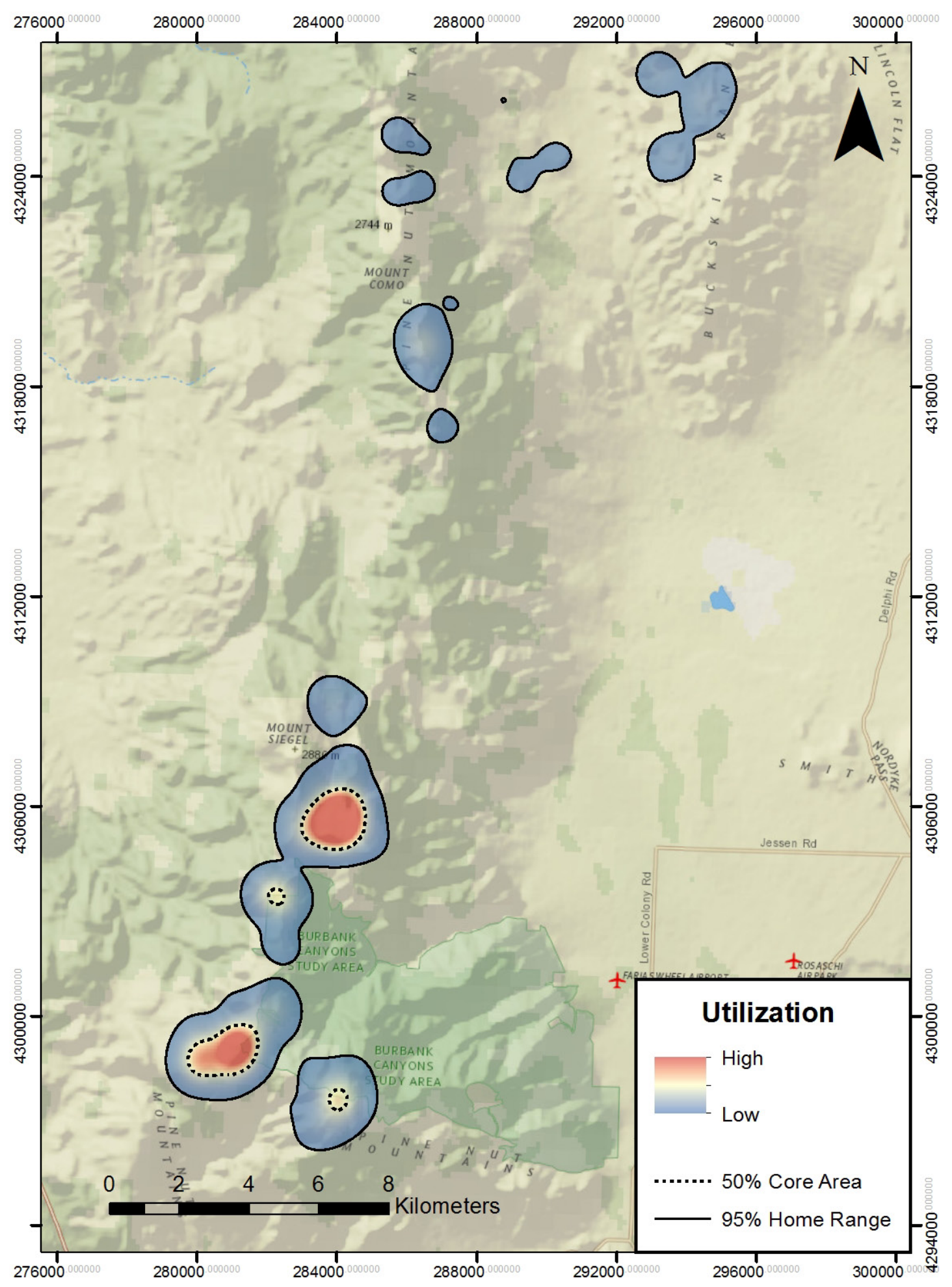

Figure 3. Map showing utilization distribution (March-August) for Bi-State sage-grouse in the southern Pine Nut Mountains, Nevada, 2011-15. 


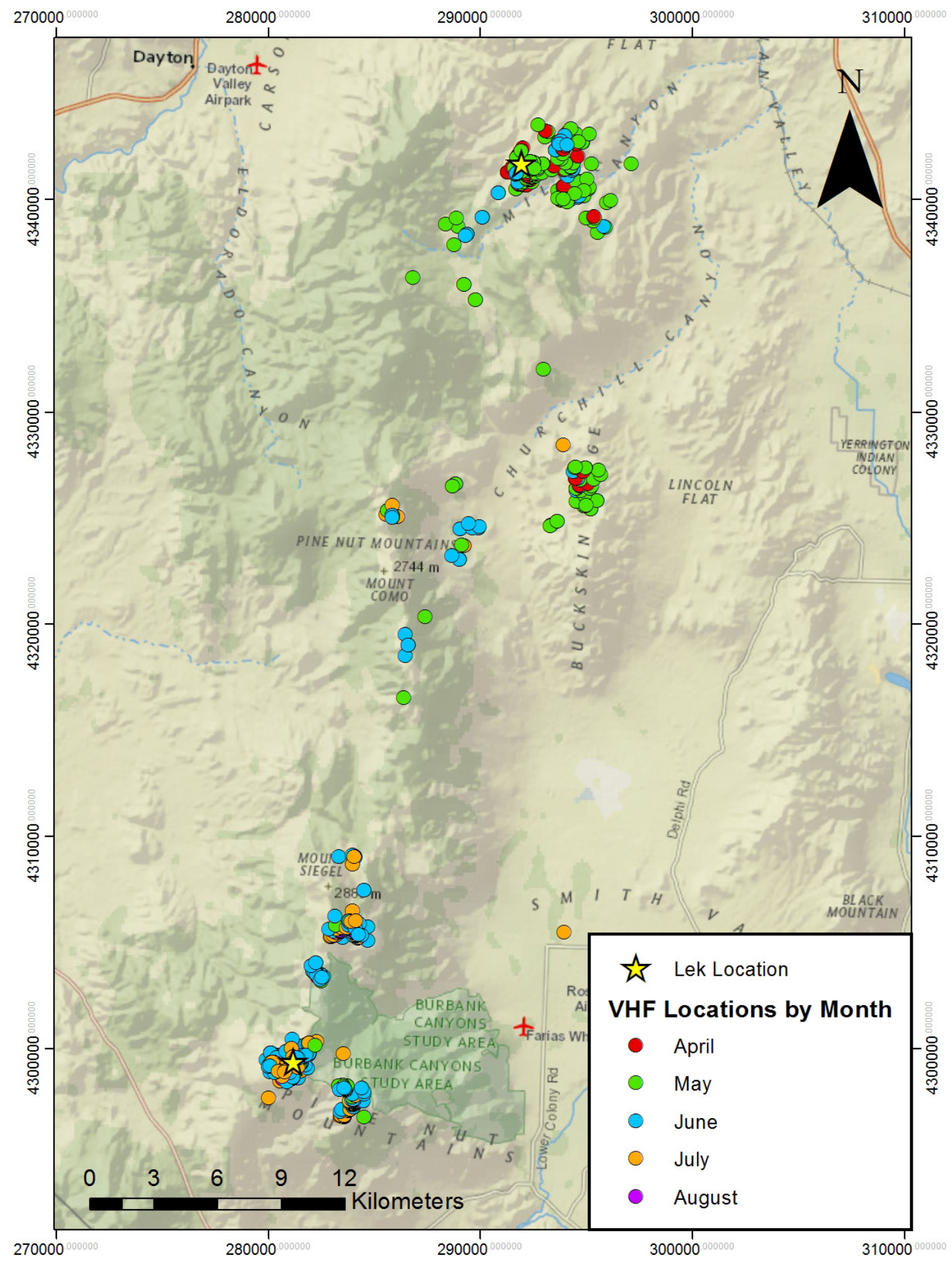

Figure 4. Map showing Very High Frequency (VHF) radio-telemetry locations of Bi-State sage-grouse by month (April-August) monitored in the Pine Nut Mountains, Nevada, 2011-15. Sage-grouse location coordinates are available upon request. 


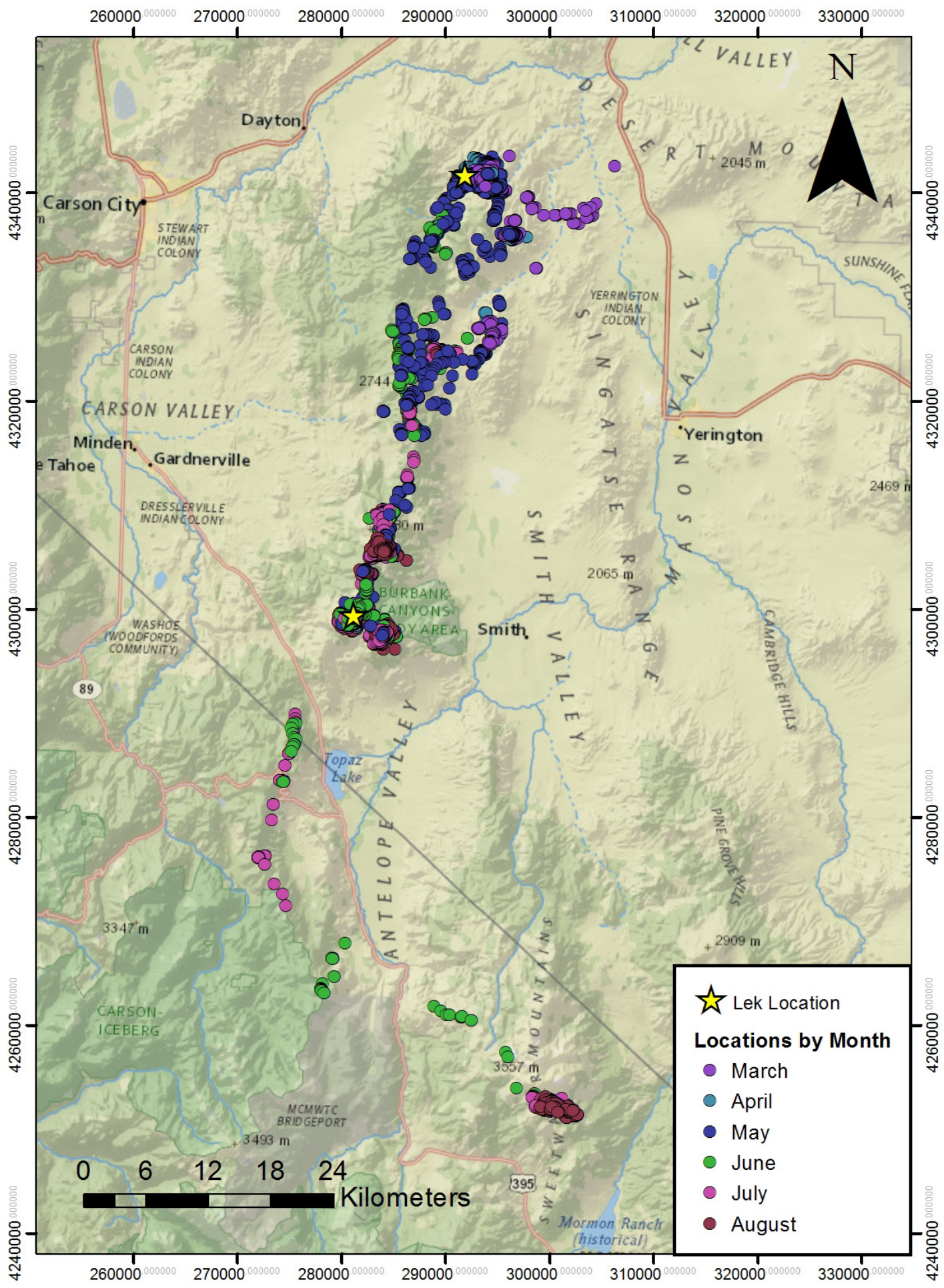

Figure 5. Map showing Global Positioning System-transmitter locations of Bi-State sage-grouse by month (MarchAugust) monitored in the Pine Nut Mountains and vicinity, Nevada and California, 2012-15. Grouse crossing the California-Nevada border in June and July represent only two adult birds, one male and one female. Sage-grouse location coordinates are available upon request. 


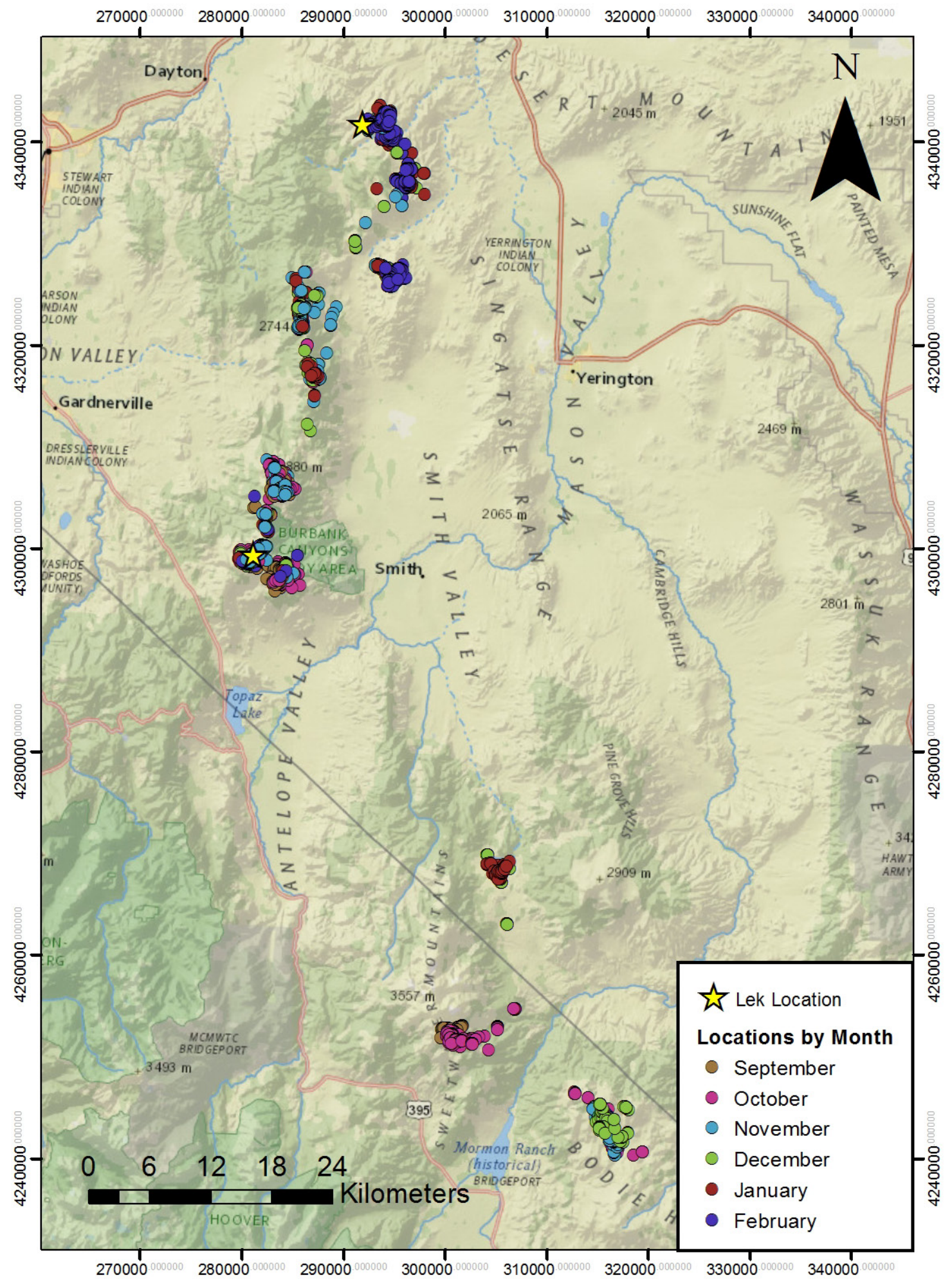

Figure 6. Map showing Global Positioning System-transmitter locations of Bi-State sage-grouse by month (September-February) monitored in the Pine Nut Mountains and vicinity, Nevada and California, 2012-15. Sagegrouse location coordinates are available upon request. 


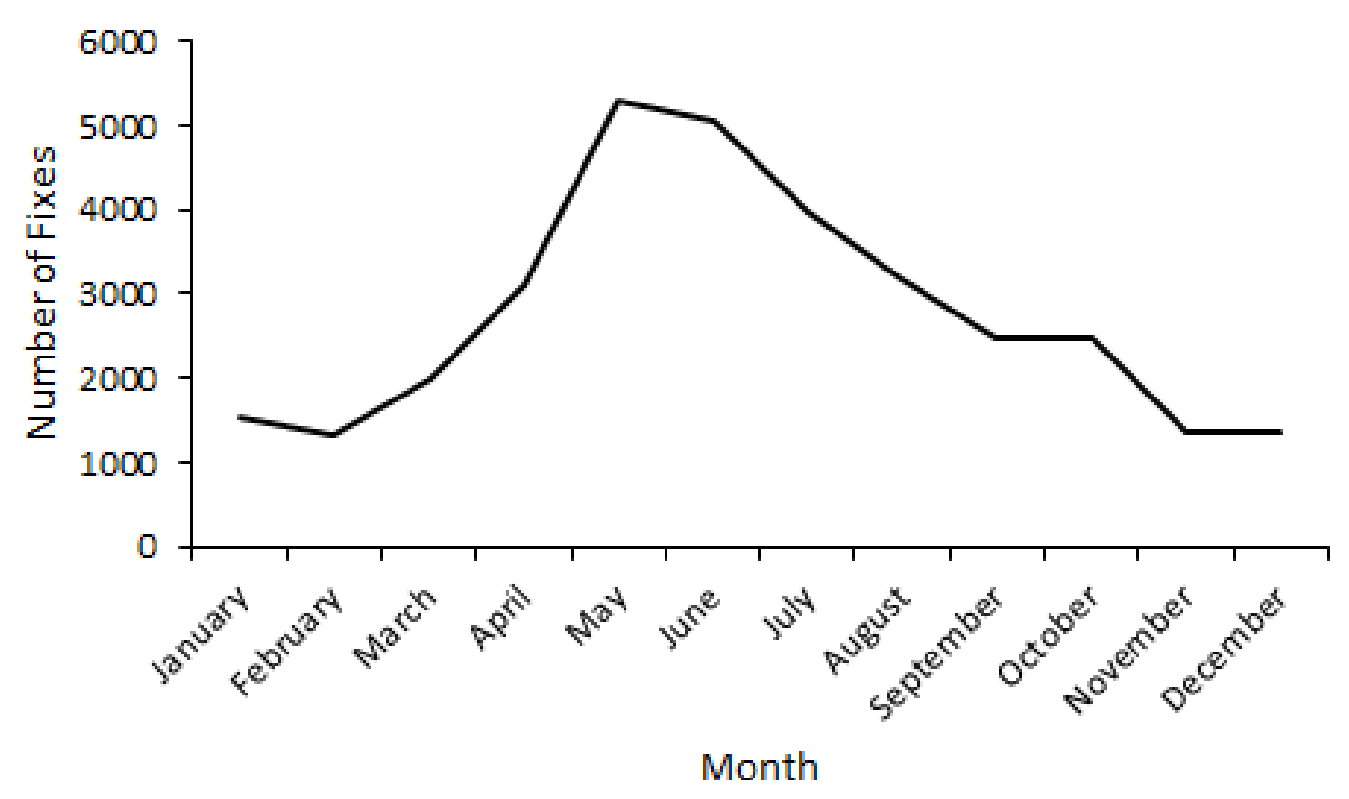

Figure 7. Graph showing number of Global Positioning System locations by month for Bi-State sage-grouse in the Pine Nut Mountains and vicinity, Nevada and California, 2012-15.

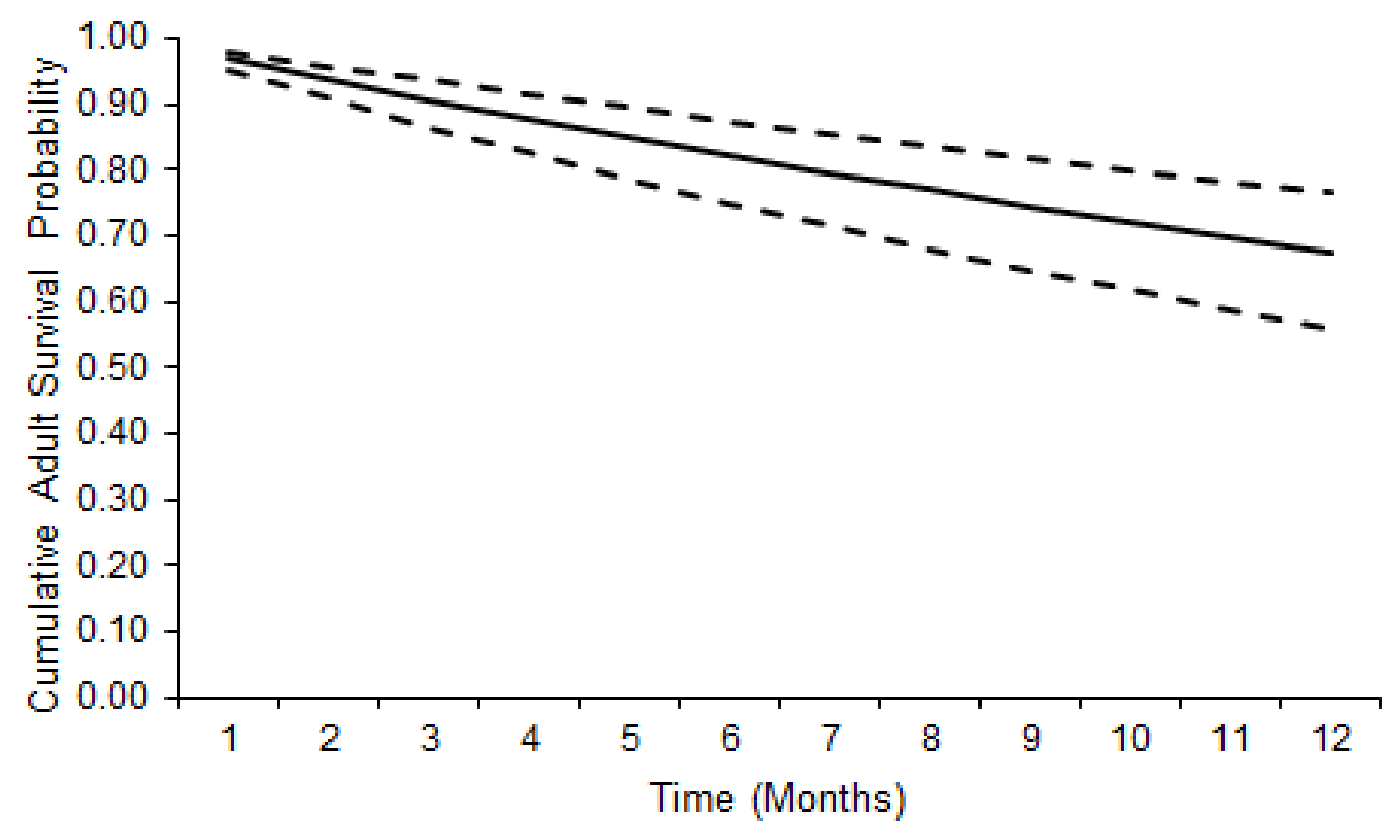

Figure 8. Graph showing cumulative average annual adult survival probabilities for Bi-State sage-grouse in the Pine Nut Mountains, Nevada and California, 2011-15. Solid line represents survival estimate, whereas dashed lines represent 95-percent confidence intervals. 


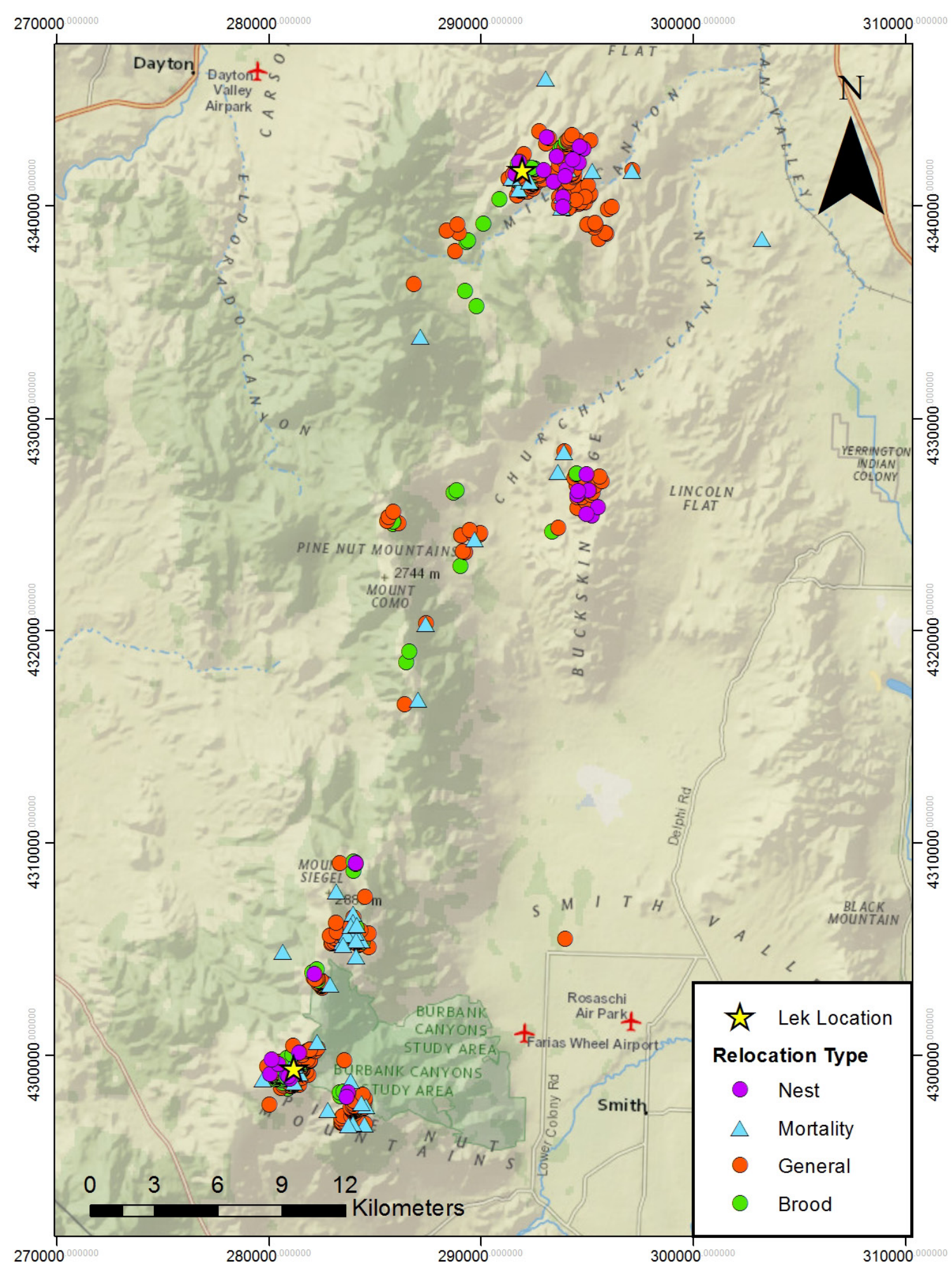

Figure 9. Map showing lek location, mortality, nest (2011-14) and brood and general telemetry locations (201115) for Bi-State sage-grouse in the Pine Nut Mountains, Nevada. Sage-grouse location coordinates are available upon request. 


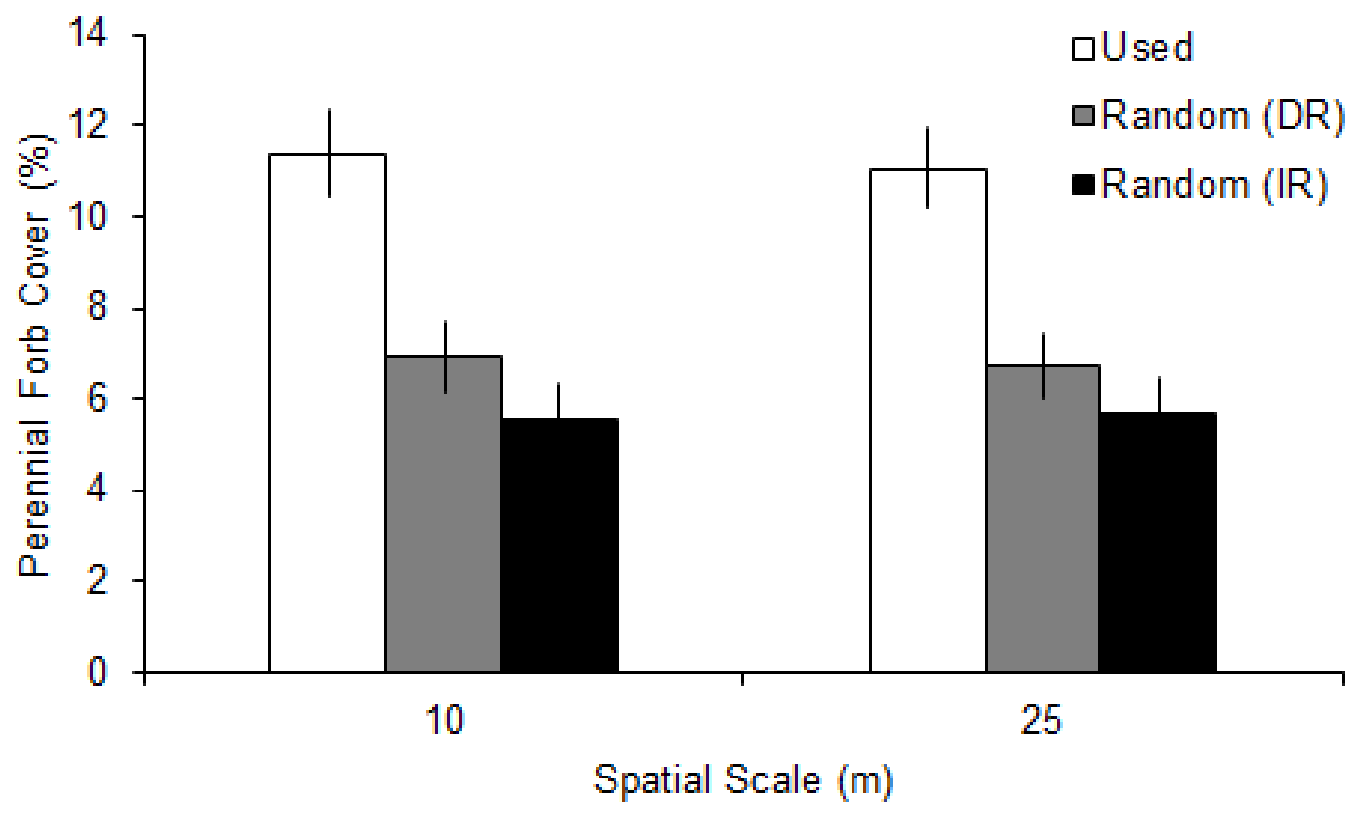

Figure 10. Graph showing average percent cover ( \pm standard error) of perennial forbs at general telemetry locations (Used) and dependent random (DR) and independent random (IR) locations in the Pine Nut Mountains, Nevada, 2011-14.

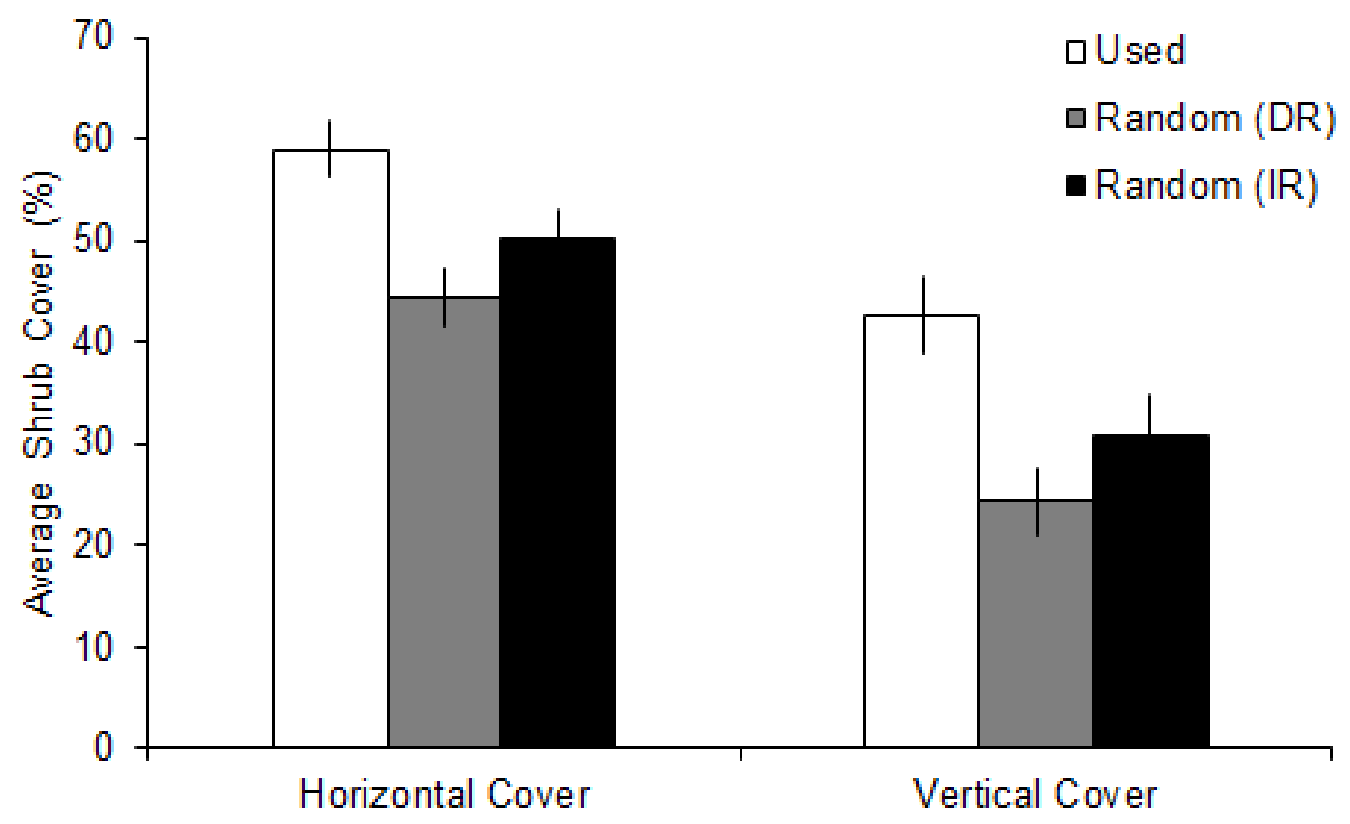

Figure 11. Graph showing average percent cover ( \pm standard error) at 0-degree and 45-degree angles (horizontal cover), and at 90-degree angle (vertical cover) for general telemetry locations (Used) and dependent random (DR) and independent random (IR) locations in the Pine Nut Mountains, Nevada, 2011-14. 


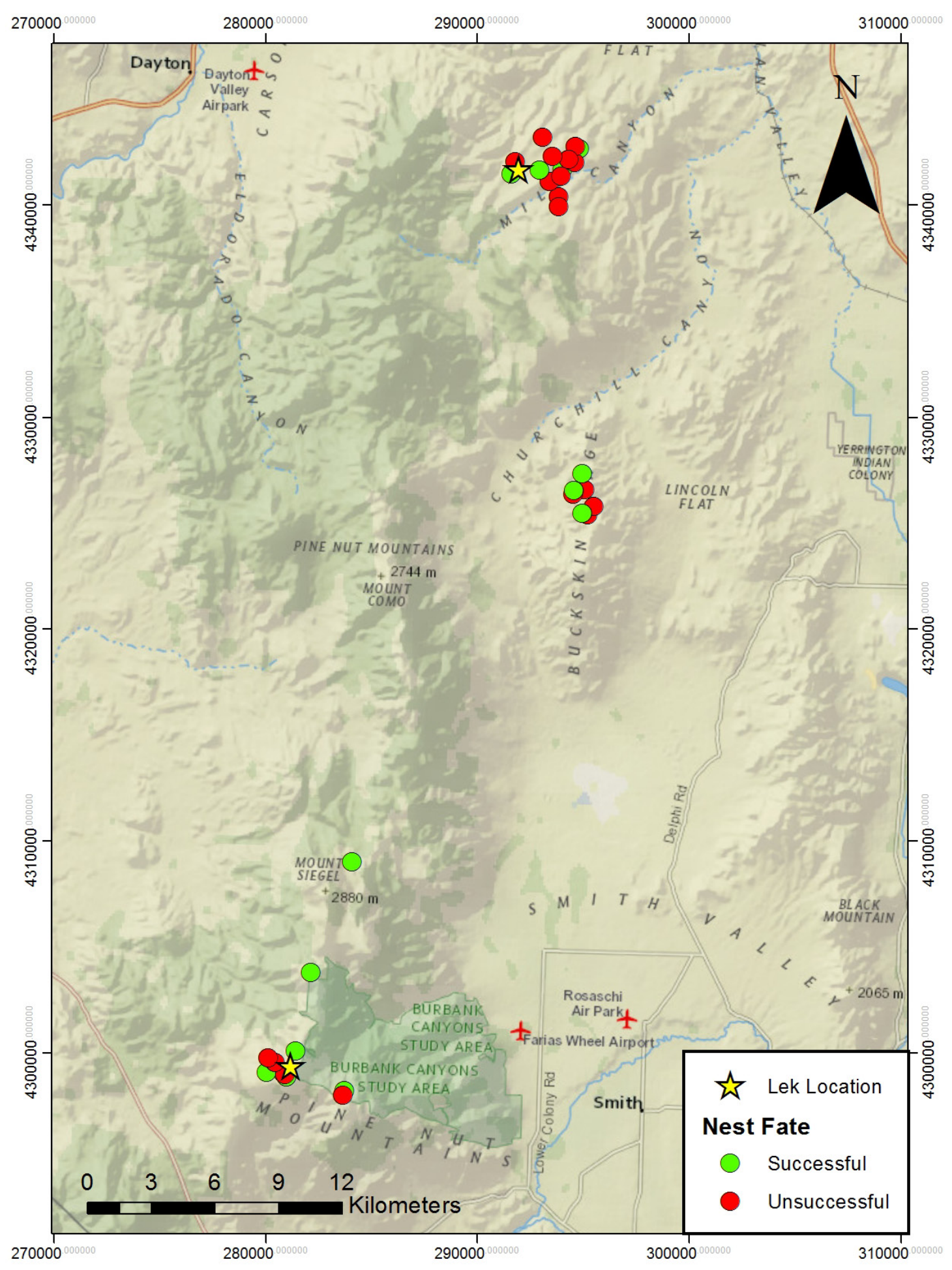

Figure 12. Map showing nest locations and nest fate for Bi-State sage-grouse in the Pine Nut Mountains, Nevada, 2011-14. Sage-grouse location coordinates are available upon request. 


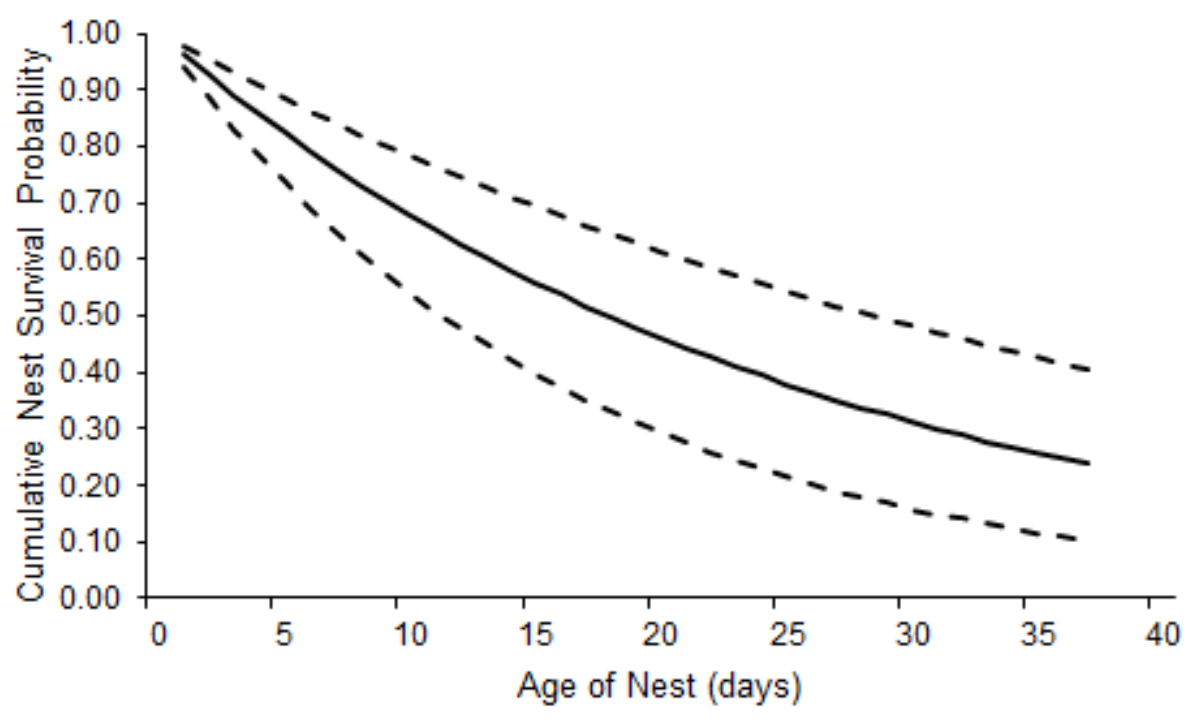

Figure 13. Graph showing cumulative nest survival probability for Bi-State sage-grouse over the 37-day egg-laying and incubation period in the Pine Nut Mountains, Nevada, 2011-15. Solid line represents survival estimate, whereas dashed lines represent 95-percent confidence intervals.

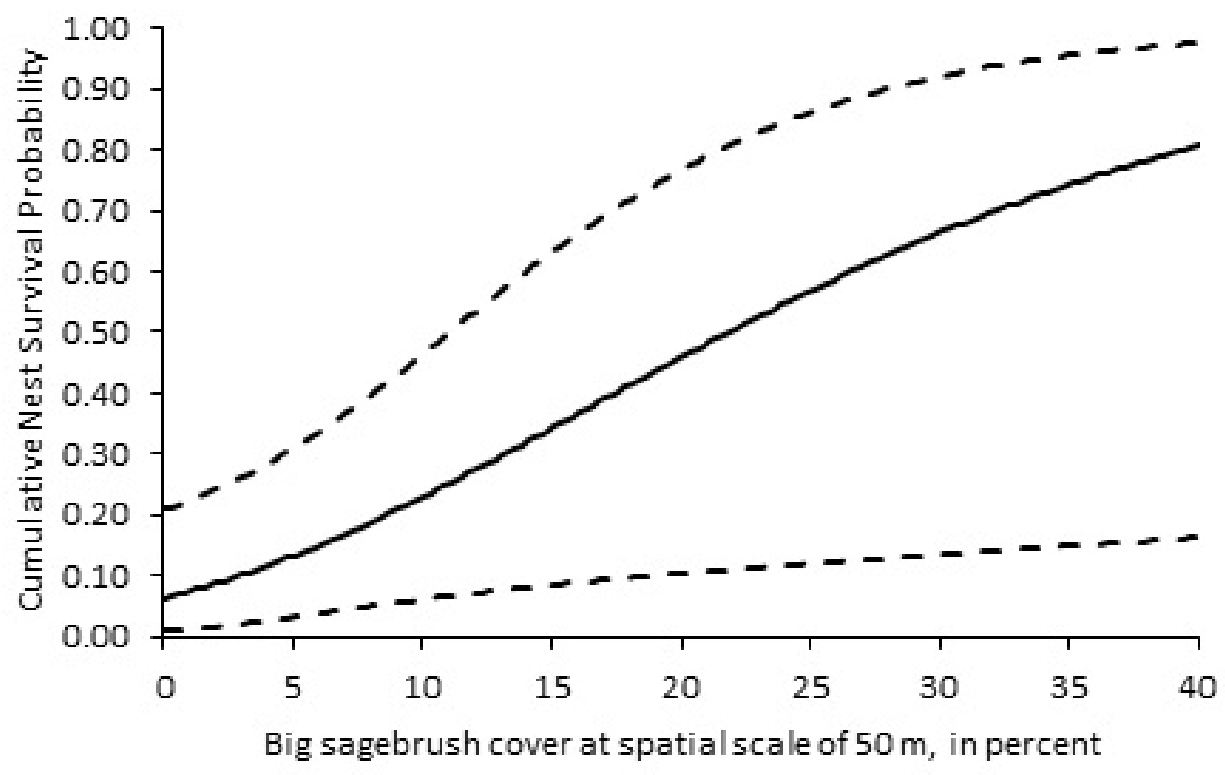

Figure 14. Graph showing cumulative nest survival probability for Bi-State sage-grouse in relation to big sagebrush cover in the Pine Nut Mountains, Nevada, 2011-13. Solid line represents survival estimate, whereas dashed lines represent 95-percent confidence intervals. 


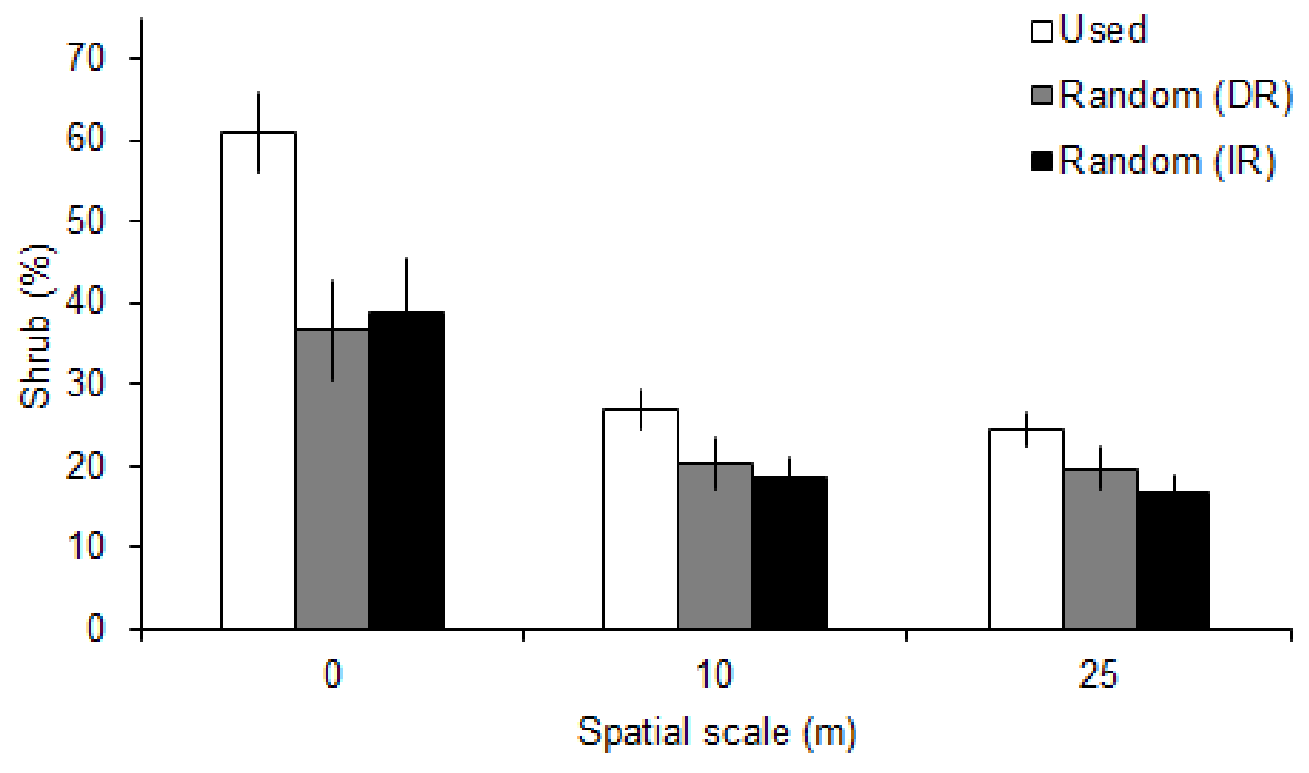

Figure 15. Graph showing average percent shrub cover ( \pm standard error) at Bi-State sage-grouse nest (Used) locations and dependent random (DR) and independent random (IR) locations in the Pine Nut Mountains, Nevada, 2011-14. The spatial scale of 0 represents habitat at the used or random location. Vertical lines represent standard errors.

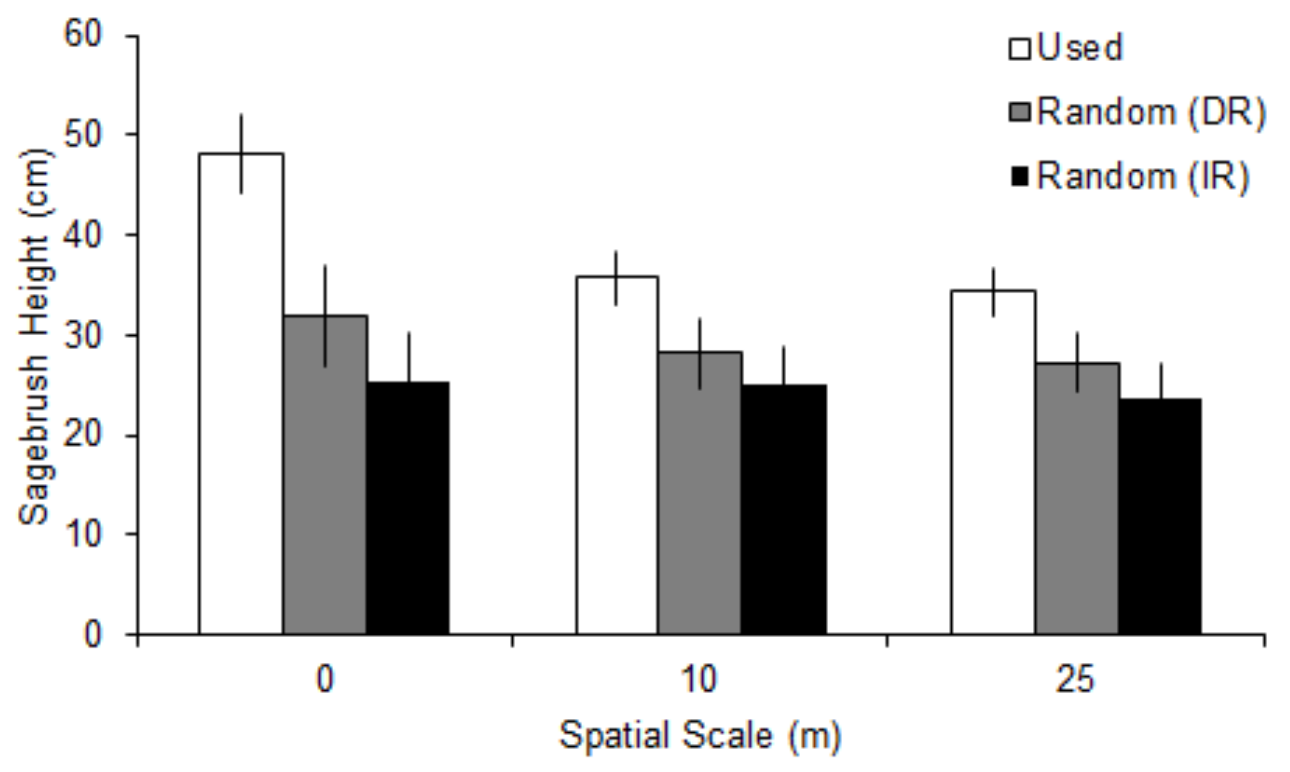

Figure 16. Graph showing average height ( \pm standard error) of sagebrush at Bi-State sage-grouse (Used) locations and dependent random (DR) and independent random (IR) locations in the Pine Nut Mountains, Nevada, 2011-14. The spatial scale of 0 represents habitat at the used or random location. Vertical lines represent standard errors. 


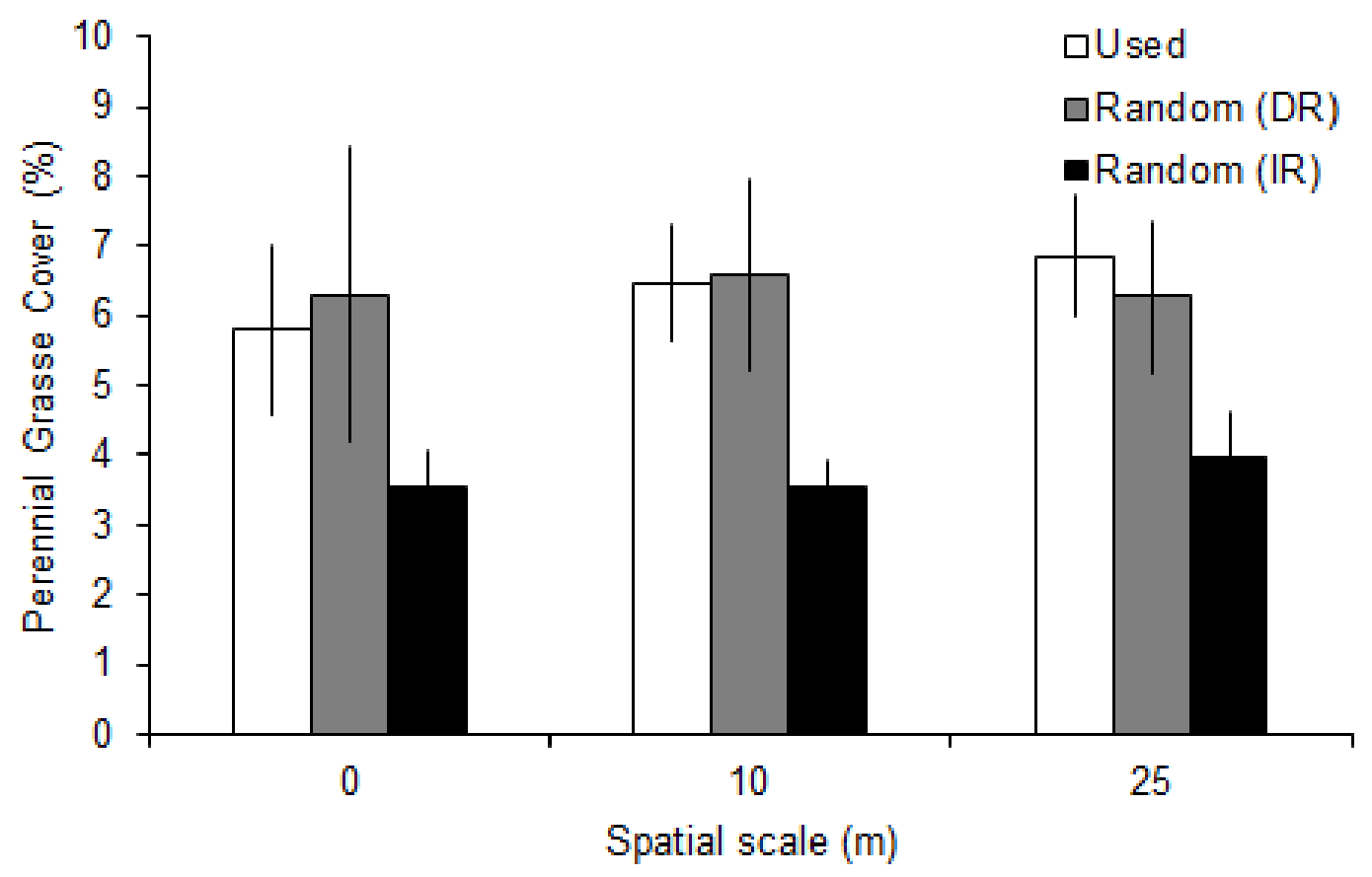

Figure 17. Graph showing average percent cover ( \pm standard error) of perennial grasses at Bi-State sage-grouse nest (Used) locations and dependent random (DR) and independent random (IR) locations in the Pine Nut Mountains, Nevada, 2011-14. The spatial scale of 0 represents habitat at the used or random location. Vertical lines represent standard errors.

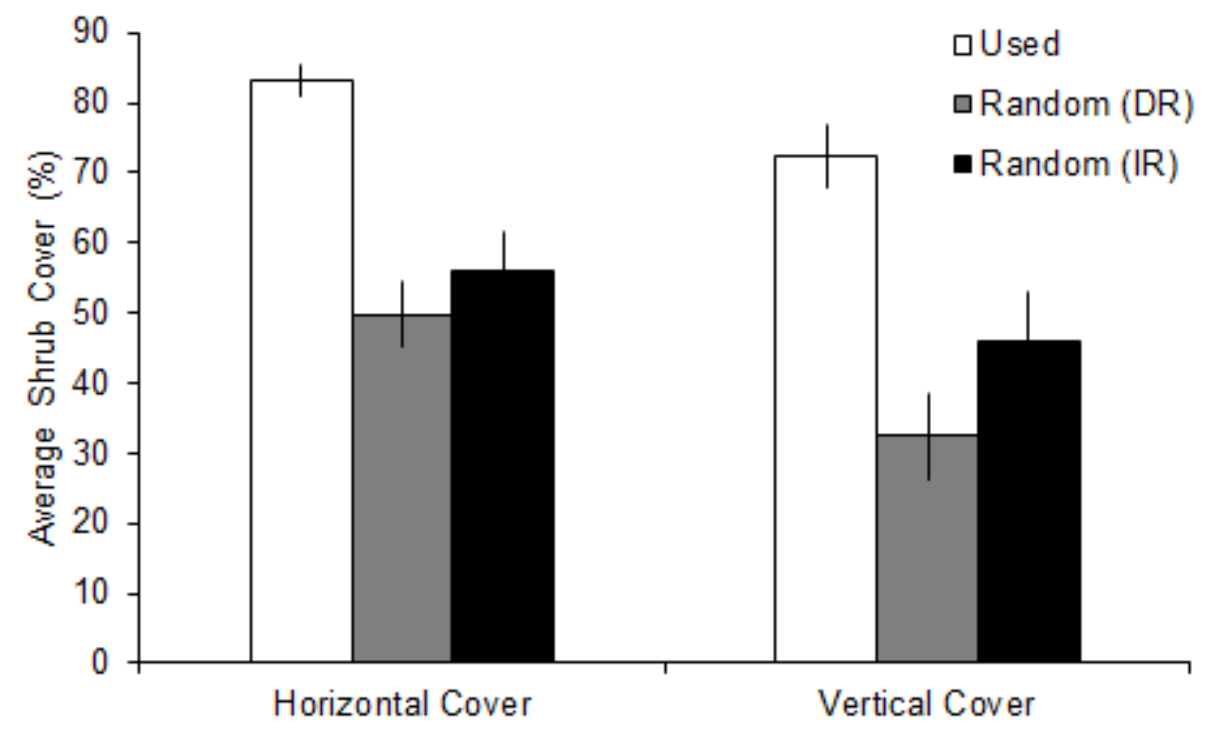

Figure 18. Graph showing average percent horizontal and vertical cover ( \pm standard error) at Bi-State sage-grouse nest (Used) locations and dependent random (DR) and independent random (IR) locations in the Pine Nut Mountains, Nevada, 2011-14. Vertical lines represent standard errors. 

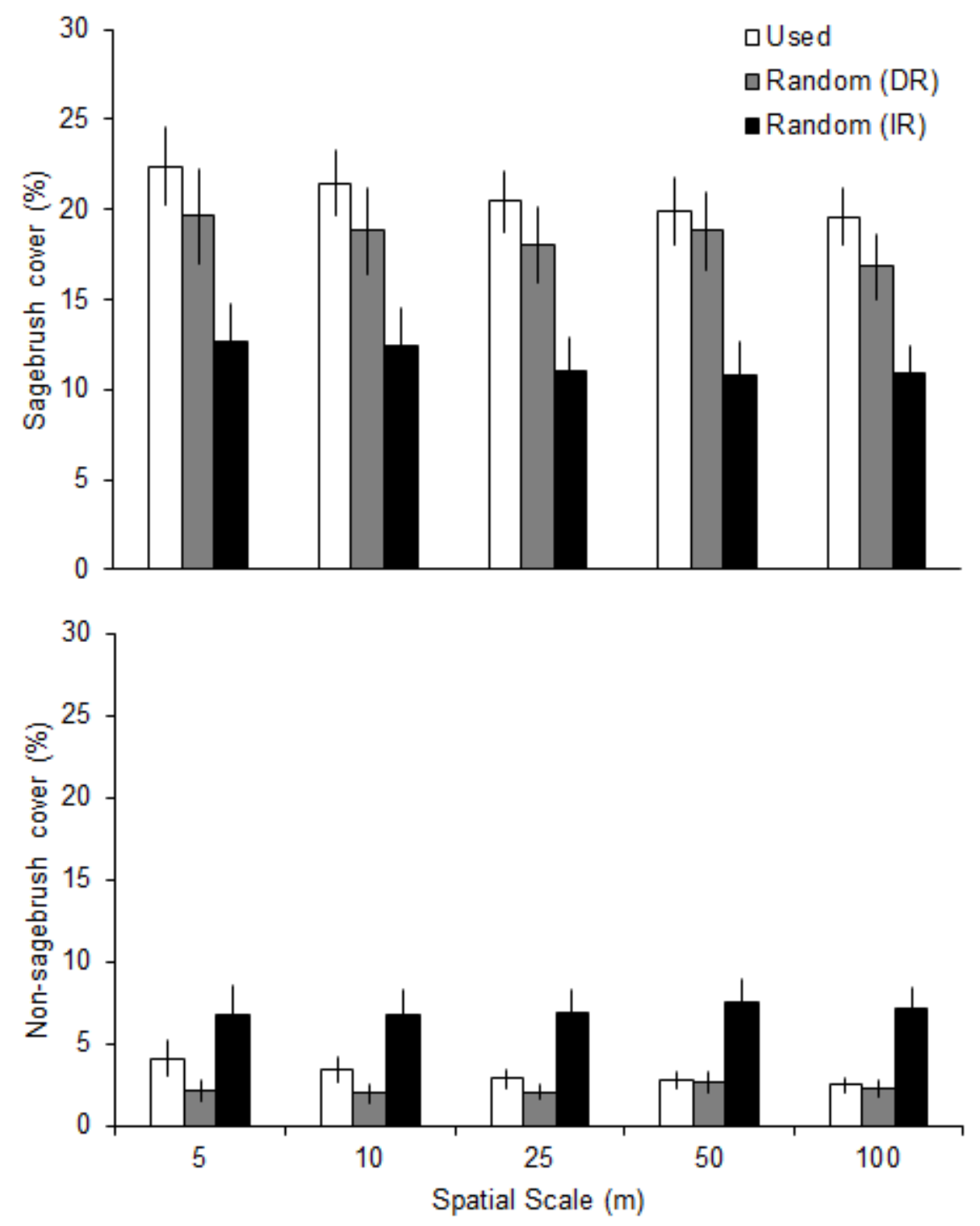

Figure 19. Graphs showing average percent sagebrush and non-sagebrush cover ( \pm standard error) at Bi-State sage-grouse nest (Used) locations and dependent random (DR) and independent random (IR) locations in the Pine Nut Mountains, Nevada, 2011-14. Vertical lines represent standard errors. 


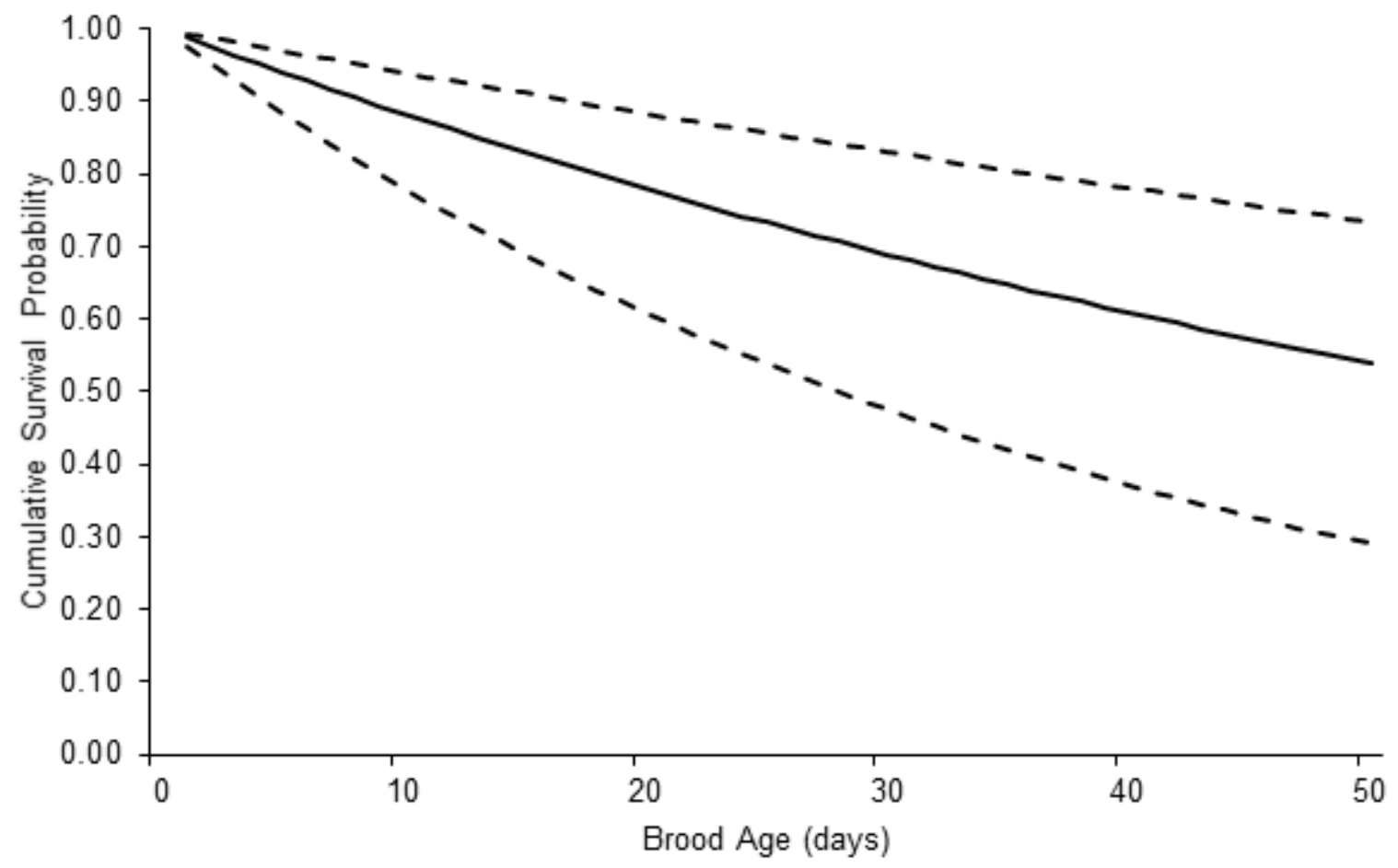

Figure 20. Graph showing cumulative survival probability for the 50-day brood-rearing phase across age of brood in the Pine Nut Mountains, Nevada, 2011-14. Solid line represents survival estimate, whereas dashed lines represent 95-percent confidence intervals.

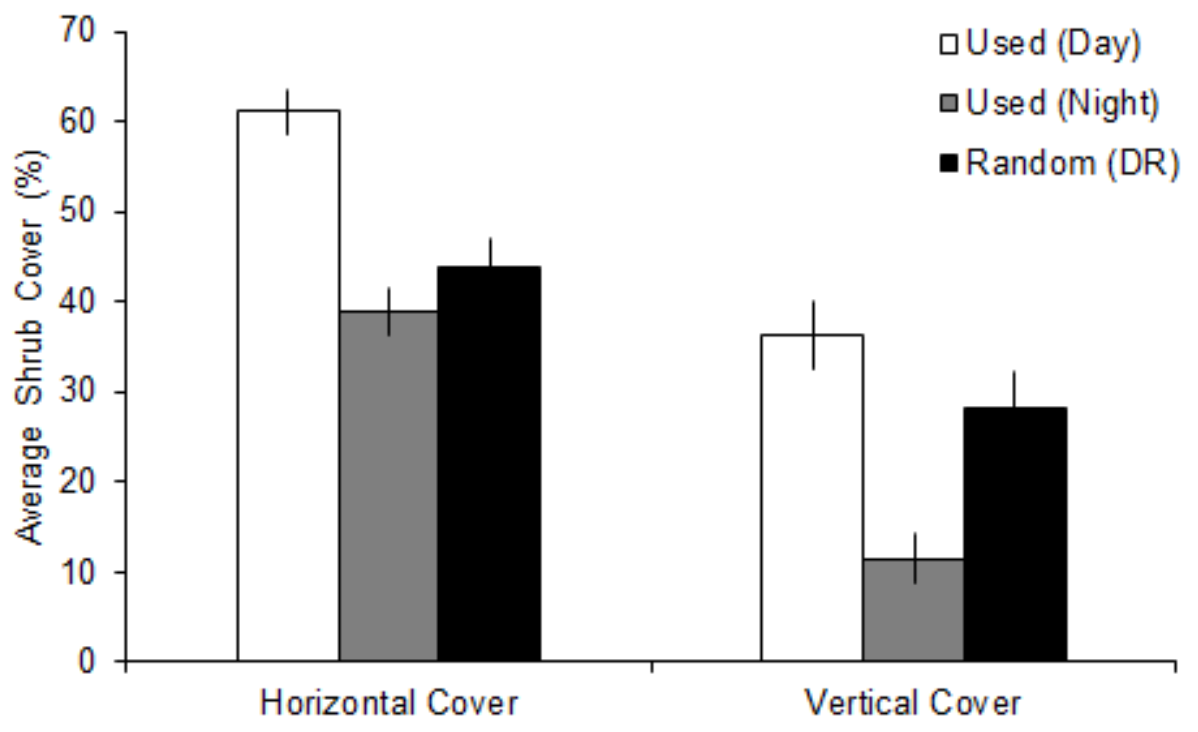

Figure 21. Graph showing average horizontal and vertical vegetation cover ( \pm standard error) at day and night brood-rearing locations and dependent random (DR) locations (based of used day location) in the Pine Nut Mountains, Nevada, 2011-14. Vertical lines represent standard errors. 

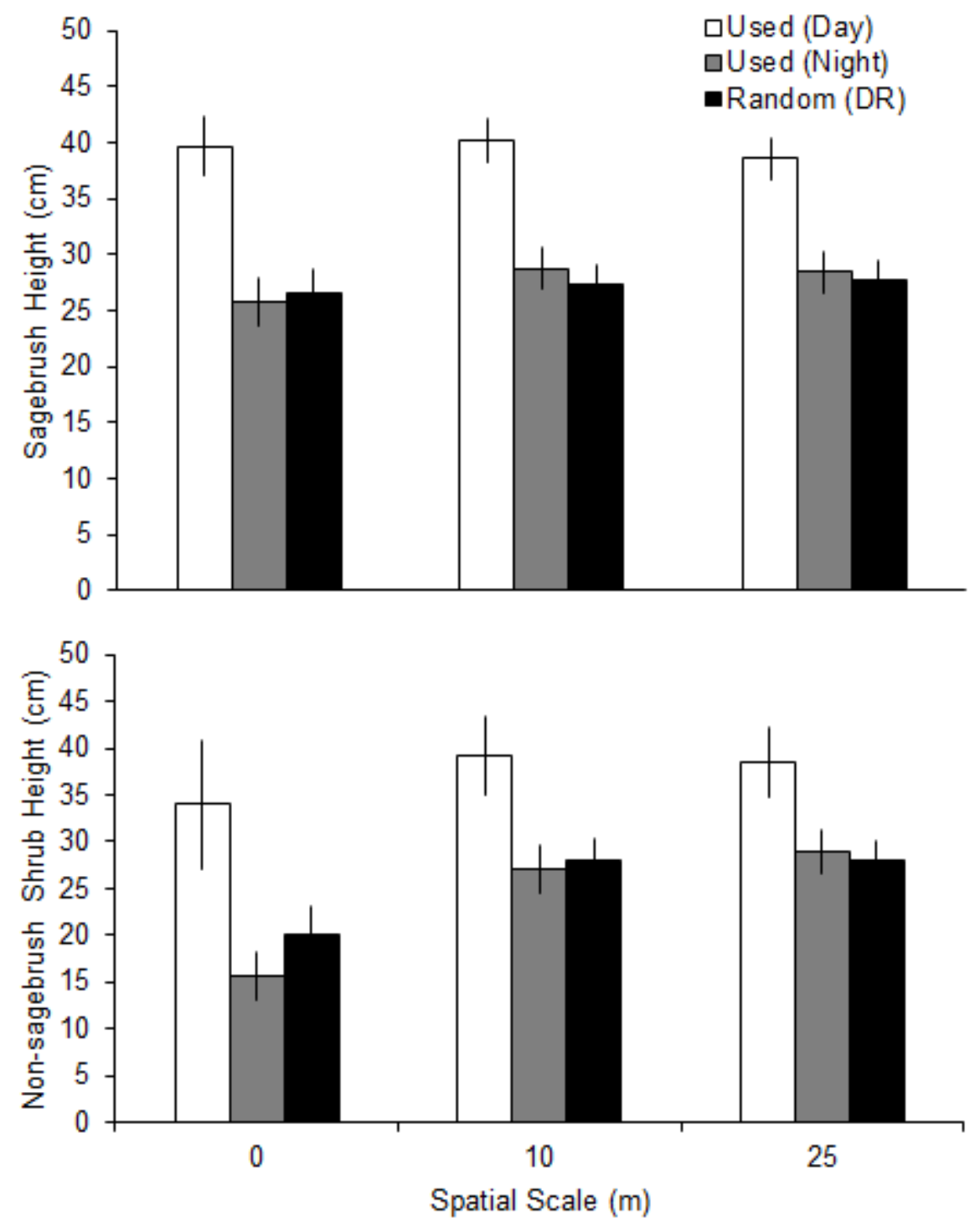

Figure 22. Graphs showing average height ( \pm standard error) of sagebrush and non-sagebrush shrub species at day and night brood-rearing locations and dependent random (DR) locations (based on used day location) in the Pine Nut Mountains, Nevada, 2011-14. The spatial scale of 0 represents habitat at the used or random location. Vertical lines represent standard errors. 


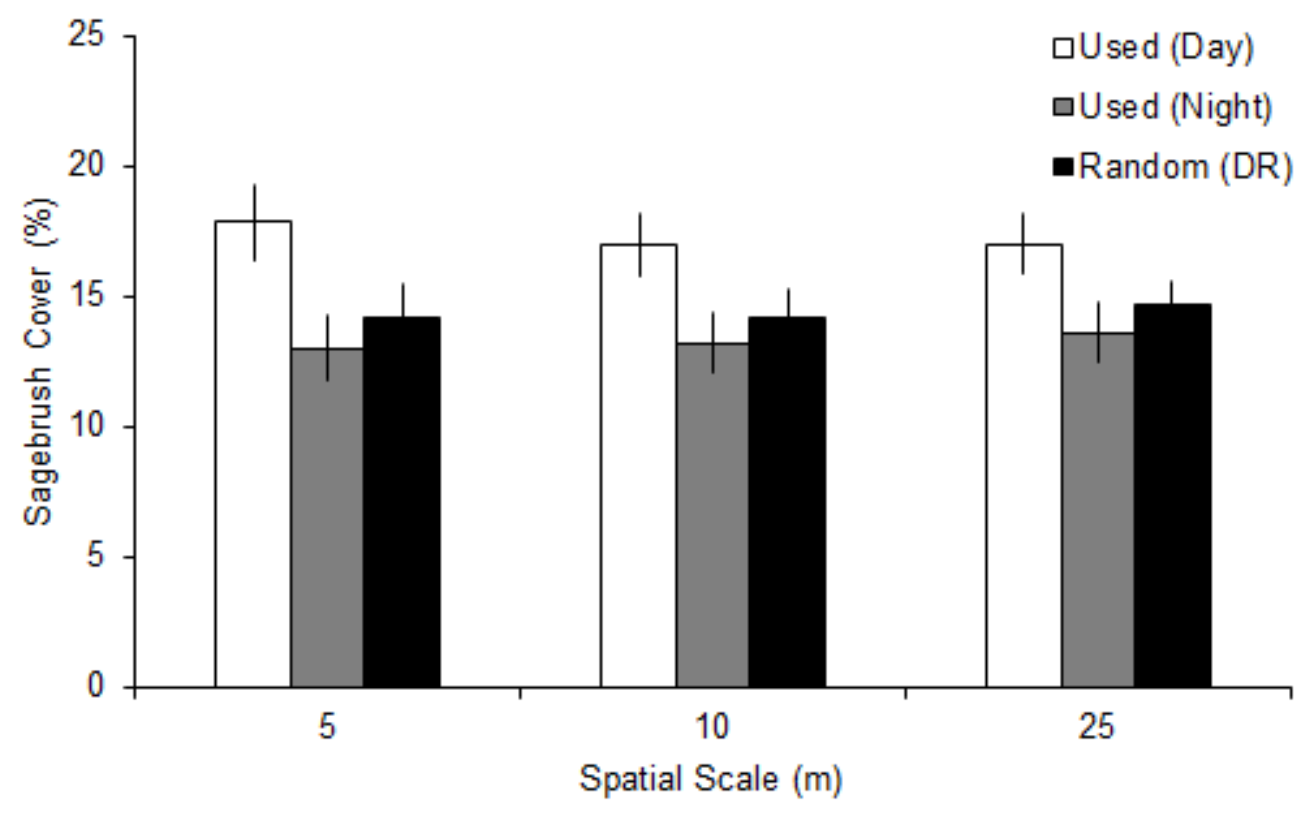

Figure 23. Graph showing average percent cover of sagebrush ( \pm standard error) at day and night brood-rearing locations and dependent random (DR) locations (based on used day location) in the Pine Nut Mountains, Nevada, 2011-14. Vertical lines represent standard errors.

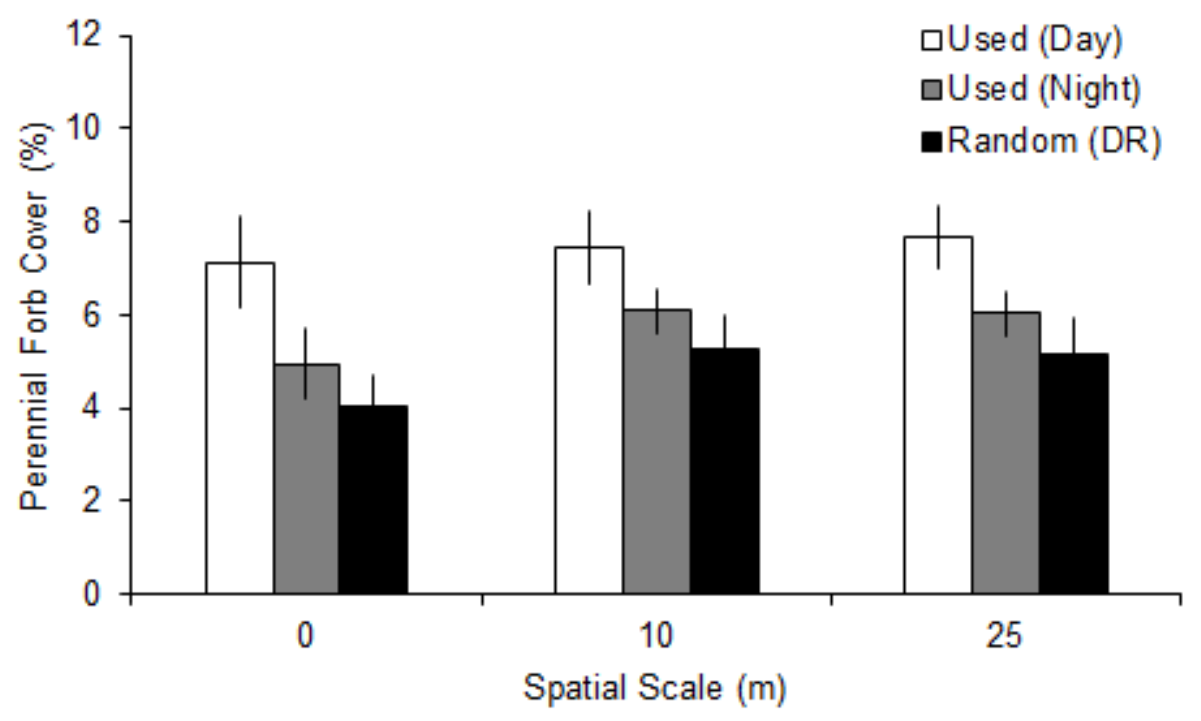

Figure 24. Graph showing average percent of perennial forb cover ( \pm standard error) at day and night broodrearing locations and dependent random (DR) locations (based on used day location) in the Pine Nut Mountains, Nevada, 2011-14. The spatial scale of 0 represents habitat at the used or random location. Vertical lines represent standard errors. 


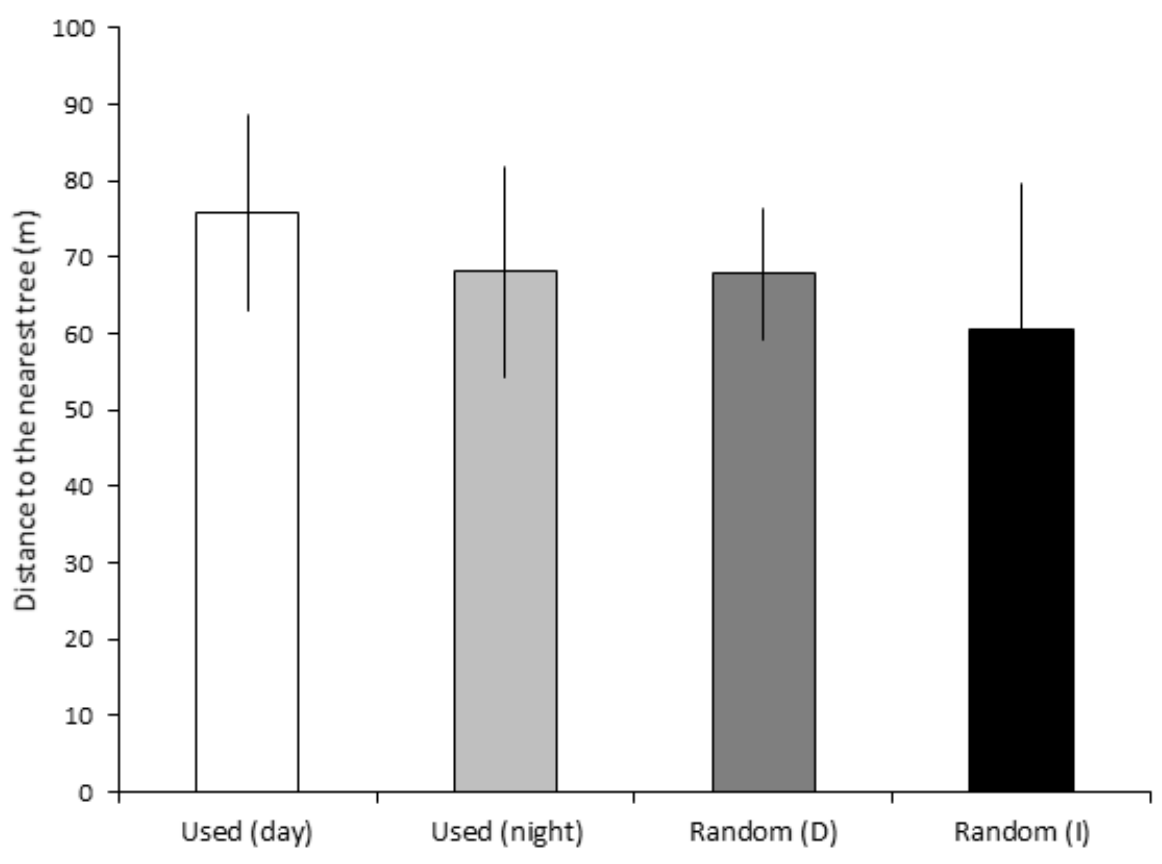

Figure 25. Graph showing average distance ( \pm standard error) from day and night brood locations and at dependent random (DR) and independent random (IR) locations to nearest pinyon and juniper trees in the Pine Nut Mountains, Nevada, 2011-13. Vertical lines represent standard errors.

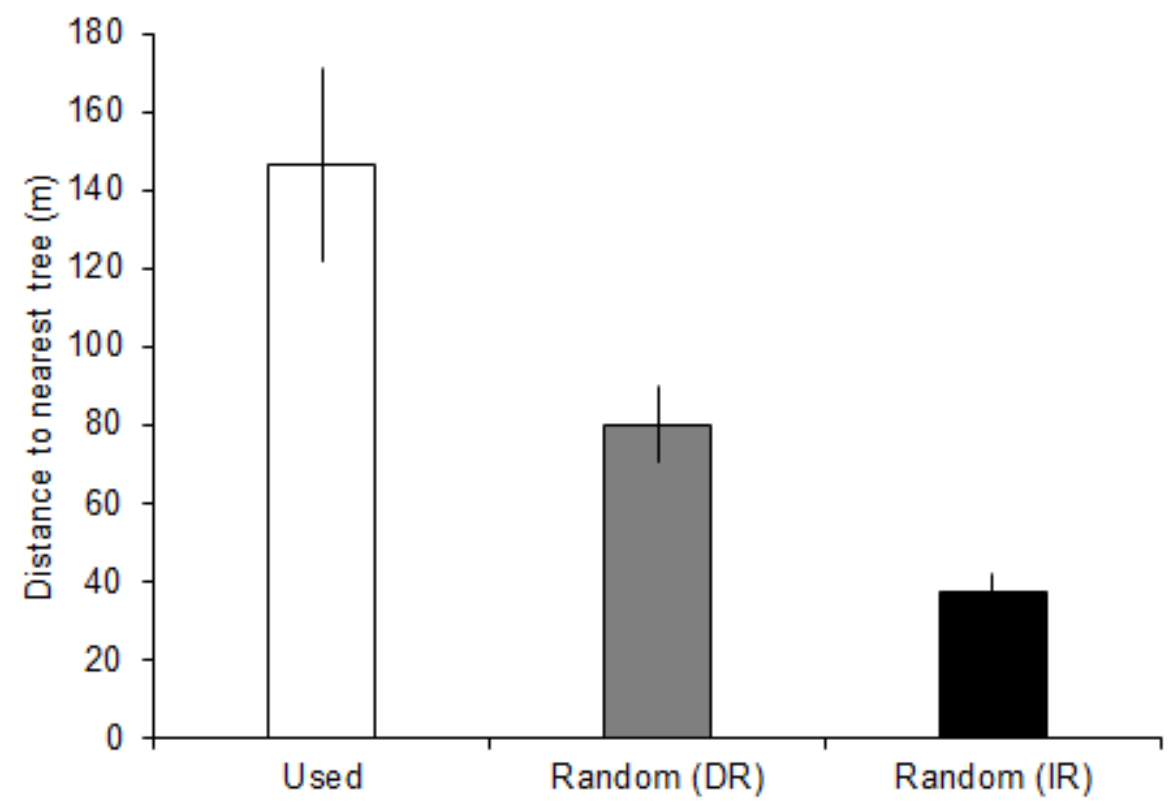

Figure 26. Graph showing average distance ( \pm standard error) from general telemetry locations and dependent random (DR) and independent random (IR) locations to pinyon and juniper trees to in the Pine Nut Mountains, Nevada, 2011-14. Vertical lines represent standard errors. 


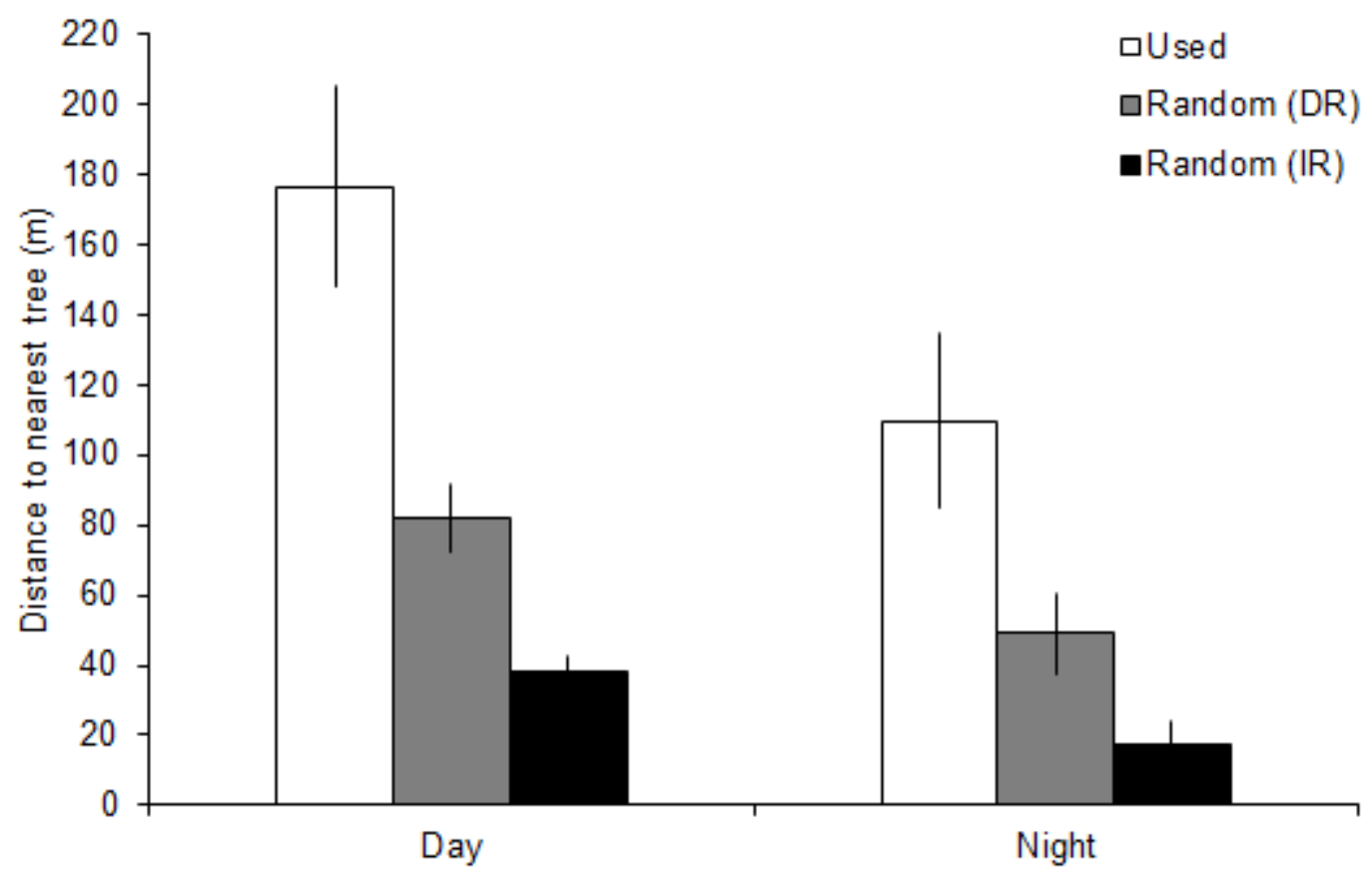

Figure 27. Graph showing average distance ( \pm standard error) from day and night general telemetry locations and dependent random (DR) and independent random (IR) locations to pinyon and juniper trees in the Pine Nut Mountains, Nevada, 2012. Vertical lines represent standard errors.

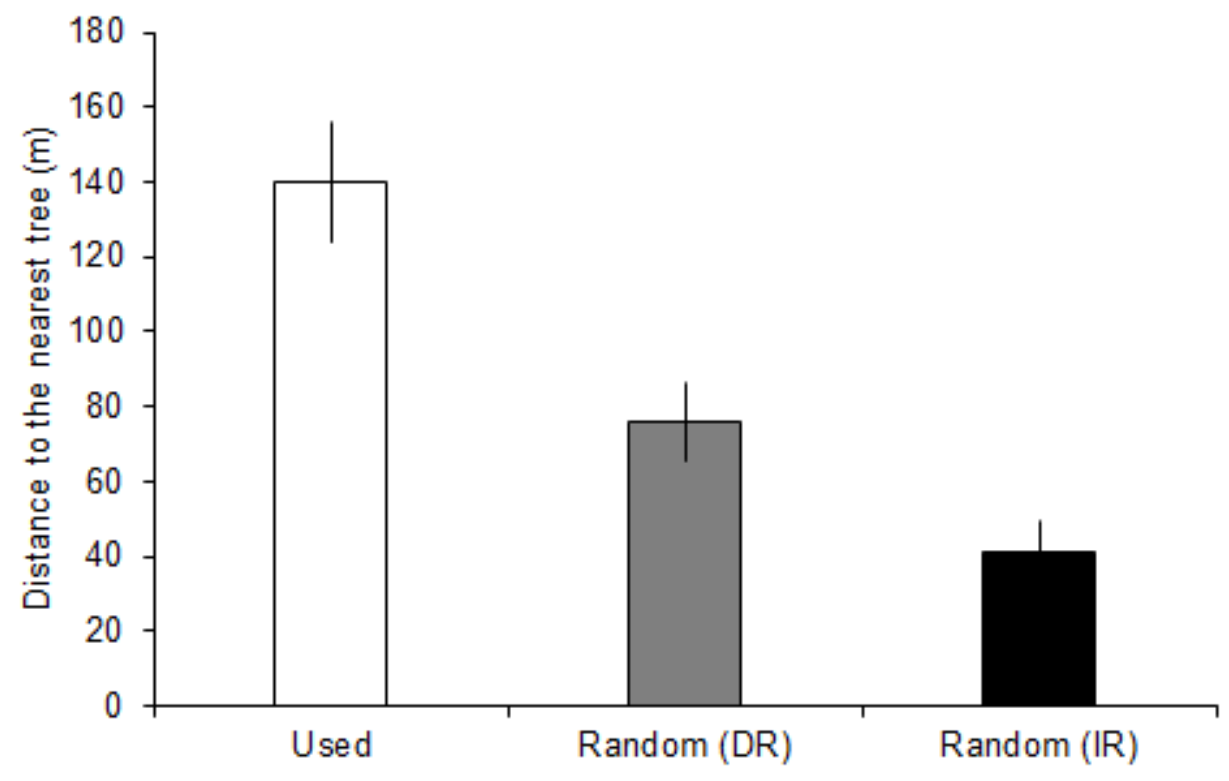

Figure 28. Graph showing average distance ( \pm standard error) from nest locations and to dependent random (DR) and independent random (IR) locations to pinyon and juniper trees to in the Pine Nut Mountains, Nevada, 2012-14. Vertical lines represent standard errors. 


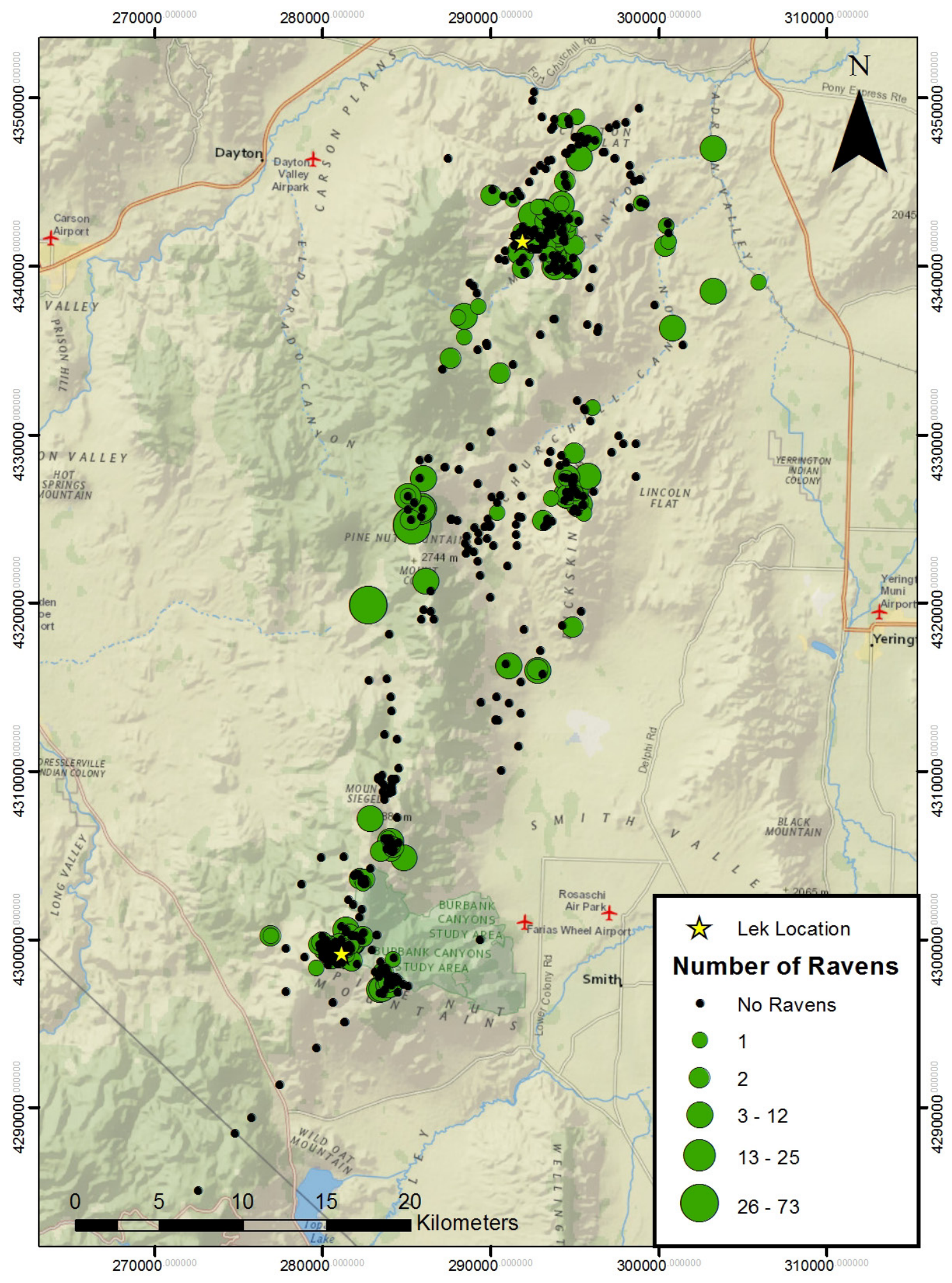

Figure 29. Map showing locations of 592 avian predator surveys and number of ravens detected during April-July in the Pine Nut Mountains, Nevada, 2011-14. Black dots represent surveys where no ravens were detected. Numbers on the map represent the largest groups of ravens detected during a survey. 


\subsection{Tables}

Table 1. Nest habitat selection at used nest locations, and dependent random (DR) and independent random (IR) locations in the Pine Nut Mountains, Nevada, 2011-14.

[Vegetation was measured at the nest bowl (0 meters), and at 10-and 25-meter distances from the nest]

\begin{tabular}{lrcrr}
\hline \multicolumn{1}{c}{ Habitat type } & $\begin{array}{c}\text { Scale } \\
\text { (meter) }\end{array}$ & Used & $\begin{array}{c}\text { Dependent } \\
\text { random } \\
\text { (DR) }\end{array}$ & $\begin{array}{c}\text { Independent } \\
\text { random } \\
\text { (IR) }\end{array}$ \\
\hline Shrub cover ( percent) & 0 & $60.9 \pm 4.9$ & $36.6 \pm 6.2$ & $39.0 \pm 6.6$ \\
& 10 & $27.1 \pm 2.4$ & $20.4 \pm 3.1$ & $18.6 \pm 2.3$ \\
& 25 & $24.6 \pm 2.1$ & $19.8 \pm 2.5$ & $16.9 \pm 2.0$ \\
\hline Sagebrush height (centimeter) & 0 & $48.1 \pm 4.1$ & $31.9 \pm 5.0$ & $25.4 \pm 5.1$ \\
& 10 & $35.7 \pm 2.7$ & $28.2 \pm 3.4$ & $25.0 \pm 3.8$ \\
& 25 & $34.3 \pm 2.4$ & $27.3 \pm 3.0$ & $23.7 \pm 3.5$ \\
\hline Perennial grass cover (percent) & 0 & $5.8 \pm 1.2$ & $6.3 \pm 2.1$ & $3.6 \pm 0.5$ \\
& 10 & $6.5 \pm 0.8$ & $6.6 \pm 1.4$ & $3.6 \pm 0.4$ \\
& 25 & $6.9 \pm 0.9$ & $6.3 \pm 1.1$ & $4.0 \pm 0.6$ \\
\hline Horizontal cover (percent) & 0 & $83.2 \pm 2.4$ & $49.7 \pm 4.7$ & $55.9 \pm 5.6$ \\
Vertical cover (percent) & 0 & $72.4 \pm 4.3$ & $32.4 \pm 6.1$ & $46.0 \pm 7.0$ \\
\hline
\end{tabular}

Table 2. Percent of all sagebrush cover and non-sagebrush cover at used nest locations, and dependent random (DR) and independent random (IR) locations in the Pine Nut Mountains, Nevada, 2011-14.

[Vegetation was measured at 5-, 10-, 25-, 50-, and 100-meter distances from the nest]

\begin{tabular}{lrccc}
\hline Habitat type & $\begin{array}{c}\text { Scale } \\
\text { (meter) }\end{array}$ & Used & $\begin{array}{c}\text { Dependent } \\
\text { random } \\
\text { (DR) }\end{array}$ & $\begin{array}{c}\text { Independent } \\
\text { random } \\
\text { (IR) }\end{array}$ \\
\hline All sagebrush cover & 5 & $22.4 \pm 2.2$ & $19.6 \pm 2.7$ & $12.7 \pm 2.0$ \\
& 10 & $21.5 \pm 1.8$ & $18.8 \pm 2.4$ & $12.5 \pm 1.9$ \\
& 25 & $20.5 \pm 1.8$ & $18.0 \pm 2.1$ & $11.1 \pm 1.7$ \\
& 50 & $19.9 \pm 1.9$ & $18.8 \pm 2.2$ & $10.8 \pm 1.7$ \\
& 100 & $19.6 \pm 1.7$ & $16.8 \pm 1.8$ & $10.9 \pm 1.5$ \\
\hline Non-sagebrush cover & 5 & $4.1 \pm 1.1$ & $2.1 \pm 0.7$ & $6.7 \pm 1.7$ \\
& 10 & $3.4 \pm 0.8$ & $2.0 \pm 0.6$ & $6.7 \pm 1.5$ \\
& 25 & $2.8 \pm 0.6$ & $2.0 \pm 0.5$ & $6.8 \pm 1.3$ \\
& 50 & $2.8 \pm 0.5$ & $2.6 \pm 0.6$ & $7.5 \pm 1.3$ \\
& 100 & $2.5 \pm 0.5$ & $2.3 \pm 0.6$ & $7.2 \pm 1.2$ \\
\hline
\end{tabular}


Table 3. Brood habitat selection at used locations, and dependent random (DR) and independent random (IR) locations in the Pine Nut Mountains, Nevada, 2011-14.

[Vegetation was measured at the nest bowl (0 meters), and at 10- and 25-meter distances from the brood. Horizontal and vertical cover measurements were averaged for the three distances]

\begin{tabular}{lrrrc}
\hline \multicolumn{1}{c}{ Habitat type } & $\begin{array}{c}\text { Scale } \\
\text { (meter) }\end{array}$ & Used & $\begin{array}{c}\text { Dependent } \\
\text { random } \\
\text { (DR) }\end{array}$ & $\begin{array}{c}\text { Independent } \\
\text { random } \\
\text { (IR) }\end{array}$ \\
\hline Sagebrush cover (percent) & 5 & $15.6 \pm 1.0$ & $14.2 \pm 1.2$ & $13.5 \pm 3.0$ \\
& 10 & $15.3 \pm 0.9$ & $14.2 \pm 1.1$ & $12.1 \pm 2.5$ \\
& 25 & $15.5 \pm 0.8$ & $14.6 \pm 1.0$ & $11.9 \pm 2.2$ \\
\hline Sagebrush height (centimeter) & 0 & $33.2 \pm 1.8$ & $26.6 \pm 2.1$ & $28.3 \pm 8.5$ \\
& 10 & $34.9 \pm 1.4$ & $27.3 \pm 1.8$ & $31.3 \pm 9.2$ \\
& 25 & $33.9 \pm 1.3$ & $27.7 \pm 1.7$ & $29.8 \pm 8.1$ \\
\hline Shrub height (centimeter) & 0 & $25.4 \pm 3.9$ & $20.0 \pm 3.1$ & $44.3 \pm 13.0$ \\
& 10 & $33.7 \pm 2.6$ & $28.0 \pm 2.3$ & $42.2 \pm 10.2$ \\
& 25 & $34.0 \pm 2.3$ & $28.0 \pm 2.1$ & $43.9 \pm 7.9$ \\
\hline Perennial forb cover (percent) & 0 & $6.1 \pm 0.6$ & $4.0 \pm 0.5$ & $3.1 \pm 0.6$ \\
& 10 & $6.8 \pm 0.4$ & $5.3 \pm 0.5$ & $5.2 \pm 1.8$ \\
& 25 & $6.9 \pm 0.4$ & $5.2 \pm 0.4$ & $4.9 \pm 1.6$ \\
\hline Horizontal cover (percent) & All & $50.7 \pm 2.0$ & $43.8 \pm 3.1$ & $56.5 \pm 7.1$ \\
Vertical cover (percent) & All & $24.9 \pm 2.6$ & $28.3 \pm 3.9$ & $48.0 \pm 11.4$ \\
\hline
\end{tabular}




\subsection{Appendix A. Evaluation of Bi-State Sage-Grouse Nest Survival Models That Consist of Habitat Characteristic Covariates for the Pine Nut Mountains, Nevada, 2011-13}

\begin{tabular}{|c|c|c|c|c|c|}
\hline Model & $\mathrm{K}$ & AICc & $\triangle \mathrm{AICC}$ & weight & er \\
\hline \multicolumn{6}{|c|}{ Shrub cover } \\
\hline Big Sage $50 \mathrm{~m}^{*}$ & 2 & 67.41 & 1.20 & 0.04 & 0.55 \\
\hline All Shrubs 50 m* & 2 & 67.68 & 1.46 & 0.03 & 0.48 \\
\hline All Tall Sages 50 m* & 2 & 67.72 & 1.51 & 0.03 & 0.47 \\
\hline All Tall Sages 100 m* & 2 & 68.15 & 1.94 & 0.03 & 0.38 \\
\hline Big Sage $100 \mathrm{~m} *$ & 2 & 68.17 & 1.95 & 0.03 & 0.38 \\
\hline All Shrubs 100 m* & 2 & 68.30 & 2.09 & 0.03 & 0.35 \\
\hline All Tall Sages 25 m* & 2 & 68.34 & 2.12 & 0.02 & 0.35 \\
\hline Big Sage 25 m* & 2 & 68.51 & 2.30 & 0.02 & 0.32 \\
\hline All Tall Sages 5 m* & 2 & 68.66 & 2.44 & 0.02 & 0.29 \\
\hline Big Sage 5 m* & 2 & 68.66 & 2.44 & 0.02 & 0.29 \\
\hline All Tall Sages 10 m* & 2 & 68.70 & 2.48 & 0.02 & 0.29 \\
\hline Quadratic Big Sage 50 m* & 3 & 68.81 & 2.60 & 0.02 & 0.27 \\
\hline Big Sage $10 \mathrm{~m}^{*}$ & 2 & 68.97 & 2.76 & 0.02 & 0.25 \\
\hline All Sages 50 m* & 2 & 69.07 & 2.86 & 0.02 & 0.24 \\
\hline Quadratic All Shrubs 50 m* & 3 & 69.14 & 2.93 & 0.02 & 0.23 \\
\hline All Sages $100 \mathrm{~m} *$ & 2 & 69.28 & 3.07 & 0.02 & 0.22 \\
\hline Quadratic All Tall Sages50 m* & 3 & 69.39 & 3.18 & 0.01 & 0.20 \\
\hline All Shrubs 25 m* & 2 & 69.43 & 3.22 & 0.01 & 0.20 \\
\hline Quadratic All Sages 50 m* & 3 & 69.69 & 3.48 & 0.01 & 0.18 \\
\hline All Sages 25 m* & 2 & 70.14 & 3.93 & 0.01 & 0.14 \\
\hline Quadratic All Shrubs 100 m* & 3 & 70.15 & 3.94 & 0.01 & 0.14 \\
\hline Quadratic All Tall Sages100 m* & 3 & 70.18 & 3.96 & 0.01 & 0.14 \\
\hline Quadratic Big Sage 100 m* & 3 & 70.20 & 3.99 & 0.01 & 0.14 \\
\hline Quadratic All Tall Sages 25 m* & 3 & 70.37 & 4.15 & 0.01 & 0.13 \\
\hline Quadratic All Tall Sages10 m* & 3 & 70.42 & 4.20 & 0.01 & 0.12 \\
\hline Quadratic Big Sage 25 m* & 3 & 70.56 & 4.34 & 0.01 & 0.11 \\
\hline Quadratic All Tall Sages5 m* & 3 & 70.60 & 4.38 & 0.01 & 0.11 \\
\hline Quadratic Big Sage 5 m* & 3 & 70.60 & 4.38 & 0.01 & 0.11 \\
\hline All Shrubs $10 \mathrm{~m}^{*}$ & 2 & 70.74 & 4.52 & 0.01 & 0.10 \\
\hline Quadratic All Sages 25 m* & 3 & 70.83 & 4.61 & 0.01 & 0.10 \\
\hline Quadratic Big Sage 10 m* & 3 & 70.83 & 4.61 & 0.01 & 0.10 \\
\hline Quadratic All Shrubs 25 m* & 3 & 71.19 & 4.98 & 0.01 & 0.08 \\
\hline Quadratic All Sages 5 m* & 3 & 71.20 & 4.98 & 0.01 & 0.08 \\
\hline Q Quadratic All Sages 100 m* & 3 & 71.29 & 5.07 & 0.01 & 0.08 \\
\hline All Shrubs $5 \mathrm{~m}$ & 2 & 71.85 & 5.64 & 0.00 & 0.06 \\
\hline Quadratic Three tip Sage $50 \mathrm{~m}$ & 3 & 71.99 & 5.78 & 0.00 & 0.06 \\
\hline All Sages $10 \mathrm{~m}$ & 2 & 72.01 & 5.80 & 0.00 & 0.06 \\
\hline All Sages $5 \mathrm{~m}$ & 2 & 72.31 & 6.10 & 0.00 & 0.05 \\
\hline Three tip Sage $10 \mathrm{~m}$ & 2 & 72.43 & 6.22 & 0.00 & 0.04 \\
\hline
\end{tabular}




\begin{tabular}{|c|c|c|c|c|c|}
\hline Model & $\mathrm{K}$ & AICC & $\triangle \mathrm{AICC}$ & weight & er \\
\hline Three tip Sage $25 \mathrm{~m}$ & 2 & 72.43 & 6.22 & 0.00 & 0.04 \\
\hline Quadratic All Shrubs $5 \mathrm{~m}$ & 3 & 72.46 & 6.24 & 0.00 & 0.04 \\
\hline Quadratic All Sages $10 \mathrm{~m}$ & 3 & 72.56 & 6.34 & 0.00 & 0.04 \\
\hline Quadratic All Shrubs $10 \mathrm{~m}$ & 3 & 72.68 & 6.46 & 0.00 & 0.04 \\
\hline Non-Sage Shrubs $100 \mathrm{~m}$ & 2 & 73.15 & 6.94 & 0.00 & 0.03 \\
\hline Quadratic Non-Sage Shrubs 100 m & 3 & 73.22 & 7.01 & 0.00 & 0.03 \\
\hline Null & 1 & 73.54 & 7.32 & 0.00 & 0.03 \\
\hline \multicolumn{6}{|c|}{ Daubenmire } \\
\hline \% Residual Grasses Height 10 m* & 2 & 66.21 & 0.00 & 0.07 & 1.00 \\
\hline \% Residual Grasses Height 25 m* & 2 & 66.64 & 0.43 & 0.06 & 0.81 \\
\hline \% Quadratic Residual Grasses Height 25 m* & 3 & 67.40 & 1.18 & 0.04 & 0.55 \\
\hline \% Quadratic Residual Grasses Height 10 m* & 3 & 67.86 & 1.65 & 0.03 & 0.44 \\
\hline \% Quadratic Mean Shrub 0 m* & 3 & 68.53 & 2.32 & 0.02 & 0.31 \\
\hline \% Quadratic Mean Residual Cover 0 m* & 3 & 68.55 & 2.34 & 0.02 & 0.31 \\
\hline \% Mean Shrub 0 m* & 2 & 68.70 & 2.49 & 0.02 & 0.29 \\
\hline \% Quadratic Mean Annual Grass 0 m* & 3 & 70.45 & 4.24 & 0.01 & 0.12 \\
\hline \% Quadratic Mean Rock 0 m* & 3 & 71.09 & 4.88 & 0.01 & 0.09 \\
\hline \% Mean Shrub 10 m* & 2 & 71.31 & 5.09 & 0.01 & 0.08 \\
\hline \% Mean Shrub 25m* & 2 & 71.40 & 5.19 & 0.01 & 0.07 \\
\hline \% Quadratic Mean Annual Grass 25 m* & 3 & 71.46 & 5.25 & 0.01 & 0.07 \\
\hline \% Quadratic Mean Perennial Grass 25 m & 3 & 71.65 & 5.44 & 0.00 & 0.07 \\
\hline \% Residual Grasses Height $0 \mathrm{~m}$ & 2 & 71.66 & 5.44 & 0.00 & 0.07 \\
\hline \% Mean Perennial Forb 25 m & 2 & 71.96 & 5.75 & 0.00 & 0.06 \\
\hline \% Quadratic Mean Perennial Grass10m & 3 & 72.30 & 6.08 & 0.00 & 0.05 \\
\hline \% Mean Litter 25 m & 2 & 72.42 & 6.20 & 0.00 & 0.05 \\
\hline \% Quadratic Mean Perennial Forb 0 m & 3 & 72.52 & 6.30 & 0.00 & 0.04 \\
\hline \% Quadratic Mean Annual Grass 10 m & 3 & 72.75 & 6.53 & 0.00 & 0.04 \\
\hline \% Quadratic Residual Grasses Height 0 m & 3 & 72.89 & 6.68 & 0.00 & 0.04 \\
\hline \% Quadratic Mean Shrub 10 m & 3 & 73.31 & 7.10 & 0.00 & 0.03 \\
\hline \% Quadratic Mean Shrub 25 m & 3 & 73.42 & 7.20 & 0.00 & 0.03 \\
\hline \% Mean Rock 25 m & 2 & 73.51 & 7.30 & 0.00 & 0.03 \\
\hline \% Quadratic Other Shrub Height 0 m & 3 & 73.52 & 7.31 & 0.00 & 0.03 \\
\hline Null & 1 & 73.54 & 7.32 & 0.00 & 0.03 \\
\hline \multicolumn{6}{|c|}{ Visual obstruction } \\
\hline Null & 1 & 73.54 & 7.32 & 0.00 & 0.03 \\
\hline Vertical Cover & 2 & 74.81 & 8.59 & 0.00 & 0.01 \\
\hline Horizontal Cover & 2 & 75.41 & 9.19 & 0.00 & 0.01 \\
\hline Quadratic Vertical Cover & 3 & 75.77 & 9.55 & 0.00 & 0.01 \\
\hline Quadratic Horizontal Cover & 3 & 77.05 & 10.84 & 0.00 & 0.00 \\
\hline \multicolumn{6}{|c|}{ Random heights } \\
\hline Null & 1 & 73.54 & 7.32 & 0.00 & 0.03 \\
\hline Average Height & 2 & 75.30 & 9.08 & 0.00 & 0.01 \\
\hline Quadratic Average Height & 3 & 77.34 & 11.12 & 0.00 & 0.00 \\
\hline
\end{tabular}

*Statistically significant models. 
Publishing support provided by the U.S. Geological Survey Science Publishing Network, Tacoma Publishing Service Center

For more information concerning the research in this report, contact the Director, Western Ecological Research Center U.S. Geological Survey 3020 State University Drive East Sacramento, California 95819 http://www.werc.usgs.gov/ 


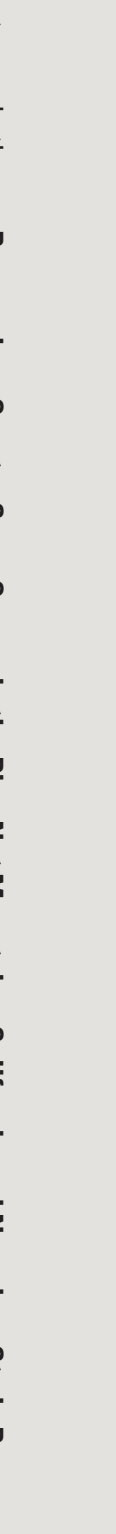

